\title{
Stress, rigidity and sediment strength control megathrust earthquake and tsunami dynamics
}

\author{
Thomas Ulrich, ${ }^{1 *}$ Alice-Agnes Gabriel, ${ }^{1}$ Elizabeth H. Madden ${ }^{2}$ \\ ${ }^{1}$ Department of Earth and Environmental Sciences, \\ Ludwig-Maximilians-Universität München, Munich, Germany \\ ${ }^{2}$ Observatório Sismológico, Instituto de Geociências, \\ Universidade de Brasília, Brasília, Brazil \\ *E-mail: ulrich@geophysik.uni-muenchen.de
}

July 31,2020

Megathrust faults host the largest earthquakes on Earth which can trigger cascading hazards such as devastating tsunamis. Determining characteristics that control subduction zone earthquake and tsunami dynamics is critical to mitigate megathrust hazards, but is impeded by structural complexity, large spatio-temporal scales, and scarce or asymmetric instrumental coverage. Here we show that tsunamigenesis and earthquake dynamics are controlled by along-arc variability in regional tectonic stresses together with depth-dependent variations in rigidity and yield strength of near-fault sediments. We aim to identify dominant regional factors controlling megathrust hazards. To this end, we demonstrate how to unify and verify the required initial conditions for geometrically complex, multi-physics earthquake-tsunami modeling from interdisciplinary geophysical observations. We present large-scale computational models of the 2004 Sumatra-Andaman earthquake and Indian Ocean tsunami that reconcile near- and far-field seismic, geodetic, geological, and tsunami observations and reveal tsunamigenic trade-offs between slip to the trench, splay faulting, and bulk yielding of the accretionary wedge. Our computational capabilities render possible the incorporation of present and emerging high-resolution 


\section{observations into dynamic-rupture-tsunami models. Our findings highlight the importance of regional-scale structural heterogeneity to decipher megathrust hazards.}

Variations in megathrust earthquake rupture behaviour are associated with tectonic, mechanical and structural factors highlighting the importance of depth-dependent and along-arc subduction zone heterogeneity (1-5). Large tsunamis may be caused by various co-seismic mechanisms including large slip to the trench, as observed during the 2011 Tohoku earthquake (6) and inferred from tsunami deposits along the Kuril trench (7), slip on splay faults (8), and inelastic co-seismic deformation generating significant uplift near the trench $(9,10)$.

Here, we hypothesize that a few regional scale subduction zone characteristics control earthquake kinematics, earthquake dynamics, and tsunami genesis. These characteristics include rock rigidity and yield strength, plate convergence rate, and regional tectonic stresses. Such features and their heterogeneities can be readily constrained by seismic, geodetic, and geological observations (e.g. (11)).

The $2004 M_{\mathrm{w}} 9.1$ Sumatra-Andaman earthquake and subsequent Indian Ocean tsunami initiated a new era of geophysical studies focused on deciphering the complex source characteristics of large subduction zone earthquakes and how these relate to tsunami generation. The earthquake's unexpectedly large moment magnitude challenged the idea that convergence rate and age of the oceanic lithosphere control the largest earthquakes on subduction interfaces (e.g., (12-14)). The Andaman trench involves a middle-aged oceanic lithosphere, aged 50-70 million years, (15), converging at relatively slow rate as low as $20 \mathrm{~mm} / \mathrm{year}$ in the Northern Andaman section (16) and historically it only hosted thrust earthquakes of less than M 7.9 (see Fig. 1a). Then, the 2004 dynamically complex rupture ripped $1300-1500 \mathrm{~km}$ of faults along the trench for 8-10 minutes and challenged data-driven analyses. Inversion of seismic and geodetic data (17-19) are complemented by less conventional data inferences, including normal modes (20), multiple centroid moment tensor (CMT) inversions (21), gravity (e.g., (22)), tsunami (e.g., (23)) or hydroacoustic waves (e.g., (24)), and seismic arrays (25). Nonetheless, data-driven source models include large variations (26) and produce synthetic tsunamis in varying agreement with satellite or inundation records (27). Furthermore, the earthquake generated a tsunami up to 30 meters high in Northern Sumatra (28), which seems at odds with slip on the shallowly dipping subduction interface. Slip on several splay faults during 
or soon after the megathrust event was inferred from seafloor mapping (29-31), tsunami modeling (32) and aftershock relocation (33). Alternatively, near-trench slip in lithified sediments at the southern end of the rupture may be responsible for the tsunami (34-38).

Rising computational resources and efficiency now allow data-integrated dynamic rupture modeling of crustal earthquakes that complements data-driven analyses. Dynamic rupture models provide physically self-consistent descriptions of how faults yield and slide, while their non-linearity and complexity limit the total number of feasible numerical experiments. These methods have unraveled complex and/or poorly instrumented events in various tectonic contexts (e.g., (39-44)). However, constraining the dynamics and extracting hazard implications from 3D dynamic models of megathrust earthquakes requires new methods that assimilate distinct data and inferences.

We here introduce a stringent forward modeling approach to evaluate the key-factors controlling earthquaketsunami behavior. Large-scale dynamic rupture modeling provides a bridge between scales harnessing the ability to uncover the physical mechanisms and parameters relevant to the co-seismic rupture of naturally complex fault networks comprising megathrusts. We connect subduction mechanics with a scenario of the 2004 Sumatra-Andaman earthquake and tsunami produced by a physics-based computational model. Evaluation against independent observations in the near- and far-field ensures that the scenario captures the key observed earthquake characteristics (magnitude, moment release, focal mechanism(s), rupture duration, teleseismic waveforms, and ground displacements) and main characteristics of the Indian Ocean tsunami. The model reveals that the interplay of a curved megathrust geometry with the along-arc variability of regional tectonic loading and plate convergence rates, and strong rigidity variations with depth near the megathrust interface, are dominant factors controlling the earthquake. We then analyze a major conundrum (45) of earthquake-tsunami interaction that is ill-constrained by observational data: the interplay of near-trench earthquake dynamics and sedimentary yielding controlling tsunami generation and propagation. We present two additional scenarios with alternative near-trench sedimentary rock strength. These demonstrate that the strength of trench sediments and the associated changes to on-fault megathrust and splay fault slip versus off-fault plastic yielding control the seafloor displacements and, in turn, the tsunami.

To model earthquake dynamics, choices about the preexisting state of stress and the friction law governing fault 


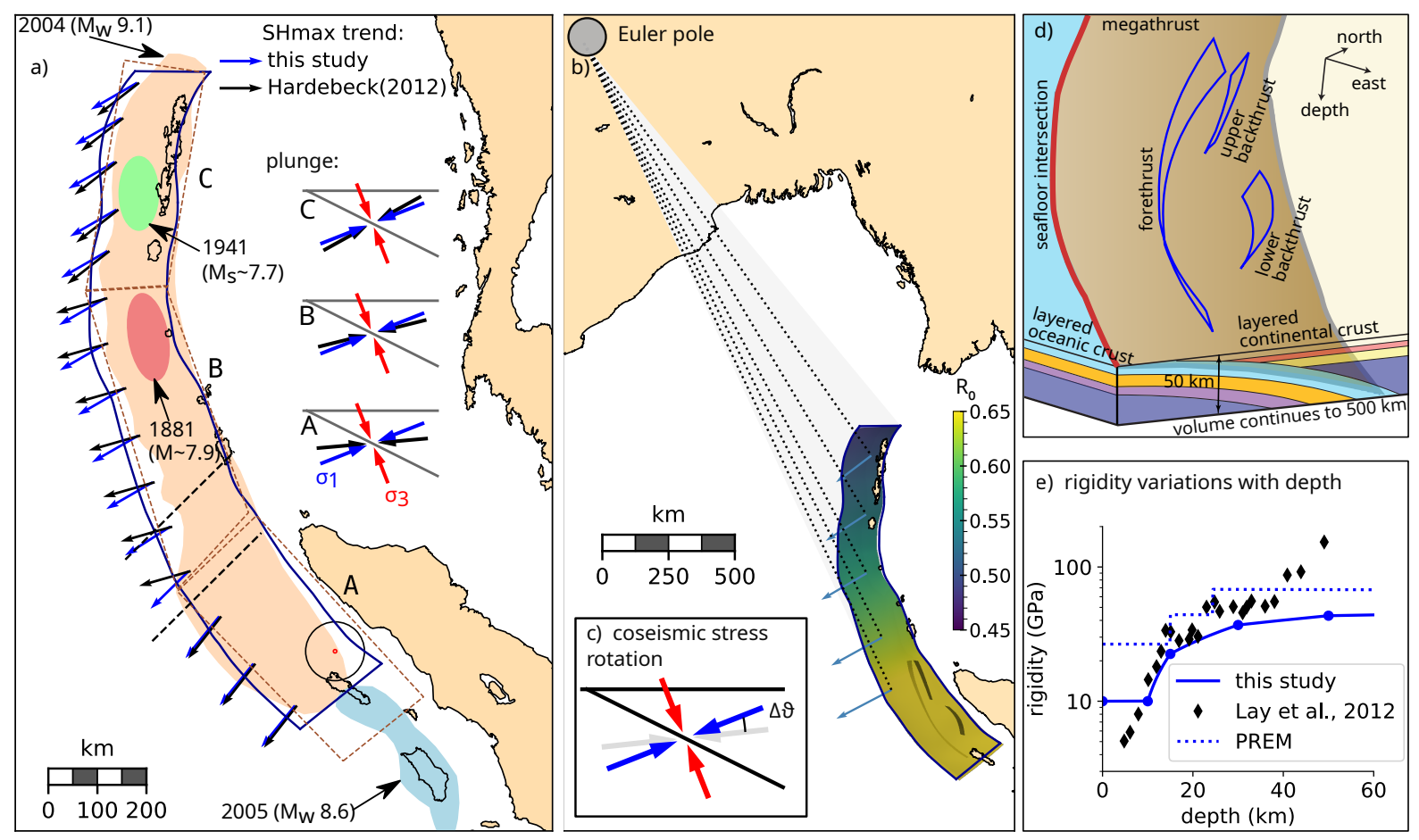

Figure 1: Key subduction characteristics constraining a 3D dynamic rupture model of a megathrust earthquake. (a) Tectonic setting and stress state of the Sumatra-Andaman subduction zone. Dark blue lines delineate the projected fault interface. Coloured shapes are slip areas for the 2004 and three historic megathrust earthquakes adapted from (46). Dashed brown polygons indicate locations of regions A, B and C over which stress parameters are inverted by (47). Arrows compare the trends of the maximum horizontal stress $\left(\mathrm{SH}_{\max }\right)$ used in this scenario (blue) to those by (47) (black). Dashed black lines bound the region where the trend of $\sigma_{1}$ linearly increases from $309^{\circ}$ to the south to $330^{\circ}$ to the north in this scenario. Cross-sections show the plunge of $\sigma_{1}$ (blue) and the minimum principal stress $\left(\sigma_{3}\right.$, red) used in this scenario, compared to those in (47) (black). Red (radius $3.5 \mathrm{~km}$ ) and black (radius $60 \mathrm{~km}$ ) circles, centered at the hypocenter, bound the region where the slip weakening distance $\left(D_{c}\right)$ increases linearly from 0.2 to $2.5 \mathrm{~m}$. (b) Modulation of the relative prestress ratio $R_{0}$ by the magnitude of the convergence rate inferred from rigid plate tectonics considerations, using the Euler pole inferred by (48) (grey dot). (c) Rotation of the maximum, $\sigma_{1}$, and minimum, $\sigma_{3}$ principal stress axes due to an earthquake (adapted from (47)). (d) Schematic view of the here adapted regional 3D structural model (e) Strong rigidity variations with depth near the megathrust interface. 
strength and sliding, as well as the lithological structure and fault geometries, are required. We constrain all required initial conditions on subduction zone scale and specific to the Sumatra-Andaman trench. Regional principal stress orientations from stress inversion are aligned with geodetic observations and combined with seismo-tectonic observations and the Mohr-Coulomb failure theory to constrain principal prestress magnitudes and fault friction parameters (Fig. 1a and Methods Sec. "Principal stress orientations"). We account for along-arc variations in convergence rate and assume over-pressurized fault fluids (Fig. 1b and Methods Sec. "Principal stress magnitudes"). Inferences of principal stress rotations after megathrust earthquakes provide direct information about the ratio of stress drop over prestress (4). We propose to constrain the co-seismic frictional strength drop on the megathrust based on stress rotation observations (see Fig. 1c and Methods Sec. "Coseismic stress rotation to constrain fault friction"). The 3D structural model (Fig. 1d and Methods Sec. "Regional lithological structure" and "Fault geometry") accounts for strong rigidity variations with depth in the near-fault region (Fig. 1e and Methods Sec. "Regional lithological structure"), bathymetry and topography, and a complex, embedded fault network consisting of the curved megathrust and three splay faults, a backthrust and two forethrusts splaying off of it. All faults intersect each other and the ocean floor, with megathrust-bathymetry intersection angles as low as $5^{\circ}$. We find that the following initial conditions are required to produce a realistic earthquake-tsunami scenario of the 2004 event: a non-Andersonian prestress state with pronounced along-arc and depth-dependent variations, near-lithostatic fluid pressure that results in low effective normal stress near the megathrust, strong frictional weakening, and sediments of high yield strength.

Regional variation of tectonic driving stresses modulated by convergence rates and the geometry of the slab and splay faults explains first-order static earthquake characteristics, such as geodetic displacements at regional distance. Along-depth variation in rock rigidity and yield strength of near-trench sediments determine rupture dynamics, such as rupture speed, as well as co-seismic uplift, and, thus, tsunami generation.

Fig. 2a shows the rupture evolution of the observationally constrained dynamic earthquake scenario of the 2004 Sumatra event. Complex rupture dynamics evolve across $1300 \mathrm{~km}$ of the fault system, including dynamic rupture transfers to both backthrusts and the forethrust. Along-depth variation in rock rigidity leads to faster rupture at 
depth and slower rupture at the trench yielding the boomerang-shaped slip pulse apparent in Fig. 2a. This pulse consists of multiple rupture fronts, which are caused by reflected waves and head waves generated at structural interfaces and the complex free surface.

Along-arc variations in convergence rates do significantly modulate earthquake evolution. These translate into modulations of stress drop and fault slip. In the hypocentral region, the subduction interface is nearly optimally oriented. While rupture is forced to initiate (Appendix Sec. "Earthquake nucleation"), locally decreased prestress reproduces spontaneous arrest immediately to the south of the hypocenter. The rupture also arrests spontaneously to the north, where lower convergence rates yield a critically lower prestress.

Our modeling insights are strengthened by the scenario's agreement with the main source characteristics of the 2004 earthquake. Its moment magnitude of $M_{w}=9.1$ agrees with the USGS referenced W phase based magnitude by (49), which falls in the lower range of inferred estimates ( $M_{w} 9.1$ to 9.3$)$ (26). The synthetic focal mechanism, with strike/dip/rake angles of $340^{\circ} / 14^{\circ} / 109^{\circ}$ (Fig. 2b) is compatible with the respective observational inferences of $336^{\circ} / 7^{\circ} / 114^{\circ}$ by USGS.The synthetic moment rate release features two main peaks and resembles source time functions inferred from teleseismic data (17)(Fig. 2c). The scenario is also in excellent agreement with all five focal mechanisms of the multi-CMT teleseismic inversion by (21) (Fig. 2b). In Appendix Sec. "Multiple point source analysis: source time functions", we detail the derivation of equivalent multiple moment tensors and source time functions from dynamic rupture models. The scenario also reproduces the amplitudes and envelopes of recorded long-period teleseismic waveforms (Fig. S2a at nine stations (Fig. S3) at periods of $150 \mathrm{~s}$ to $500 \mathrm{~s}$ with an average rRMS of 0.8 (see Appendix Sec. "Teleseismic model validation”)).

Figure 3 shows the rupture speed and slip characteristics along the megathrust from the dynamic rupture scenario. The speed of the modeled rupture front is slower than the S-wave speed of the host rocks (Fig 3a) everywhere except in a narrow band around $10 \mathrm{~km}$ depth. Localized supershear rupture is triggered during the mixed-mode nucleation phase of rupture due to reflected and trapped waves in the accretionary wedge. Shallow supershear rupture is prevented by off-fault plastic yielding. Rupture speed strongly varies along-depth due to the incorporated rigidity variations (Fig. 1e). The average speed resembles observational Rayleigh wave (50) and acoustic (51) 
inferences including along-arc variations (Fig. 2d). The scenario captures changes in rake along megathrust strike, from thrusting in the south to increasingly oblique faulting farther north (Fig. 3b). This variation follows the change in the strike of the non-planar megathrust relative to the laterally varying regional loading.

The dynamic rupture scenario yields a smooth fault slip distribution with along-arc variations (Fig. 3c). Regions of high slip at the trench alternate with flatter portions of the shallow interface that experience less slip. Synthetic fault slip agrees in terms of along-arc and along-depth distribution to first order with data-driven kinematic models (Fig. 3d,e).

Near-field horizontal and vertical ground displacements reproduce observations (Fig. 2e,f) in terms of amplitude and orientation. In the far-field (Fig. S1), the synthetics match recorded orientations but systematically overestimate ground displacements. We denote deviations to spatial and temporal model limitations. The dynamic scenario does not account for Earth curvature, small-scale 3D crustal structure in the far-field, nor the contribution of after-slip. Near-field synthetics may be affected by the simplistic treatment of earthquake nucleation and arrest in our model.

All three splay faults incorporated in the model are dynamically activated (Fig. 2a) and cause a noticeable signature in uplift and subsidence (Fig. 2f). The splays host significantly less slip (6-8 m) than the subduction interface (up to $40 \mathrm{~m}$ ), however, slip efficiently transfers into vertical uplift due to their steeper dip. The total contribution of splay fault slip to vertical uplift remains limited in spatial extent and amplitude.

While outer-rise aftershock sequences help to constrain the extent of slip to the trench during megathrust ruptures (52), the balance between shallow slip and off-fault yielding remains elusive from geodetic and seismic observations. However, both effects have been shown to impact vertical uplift $(45,53)$ and therefore may influence tsunami behavior. To address this, we model tsunami genesis and propagation sourced by dynamic earthquake rupture as detailed in Methods Sec. "Tsunami modeling". Synthetic tsunamis are generated from the time-dependent horizontal and vertical coseismic seafloor displacements.

Relative to the dynamic-rupture scenario described previously, we vary the yield strength of near-trench sediments in two alternative dynamic scenarios with weaker and stronger near-trench sediments, yielding respec- 


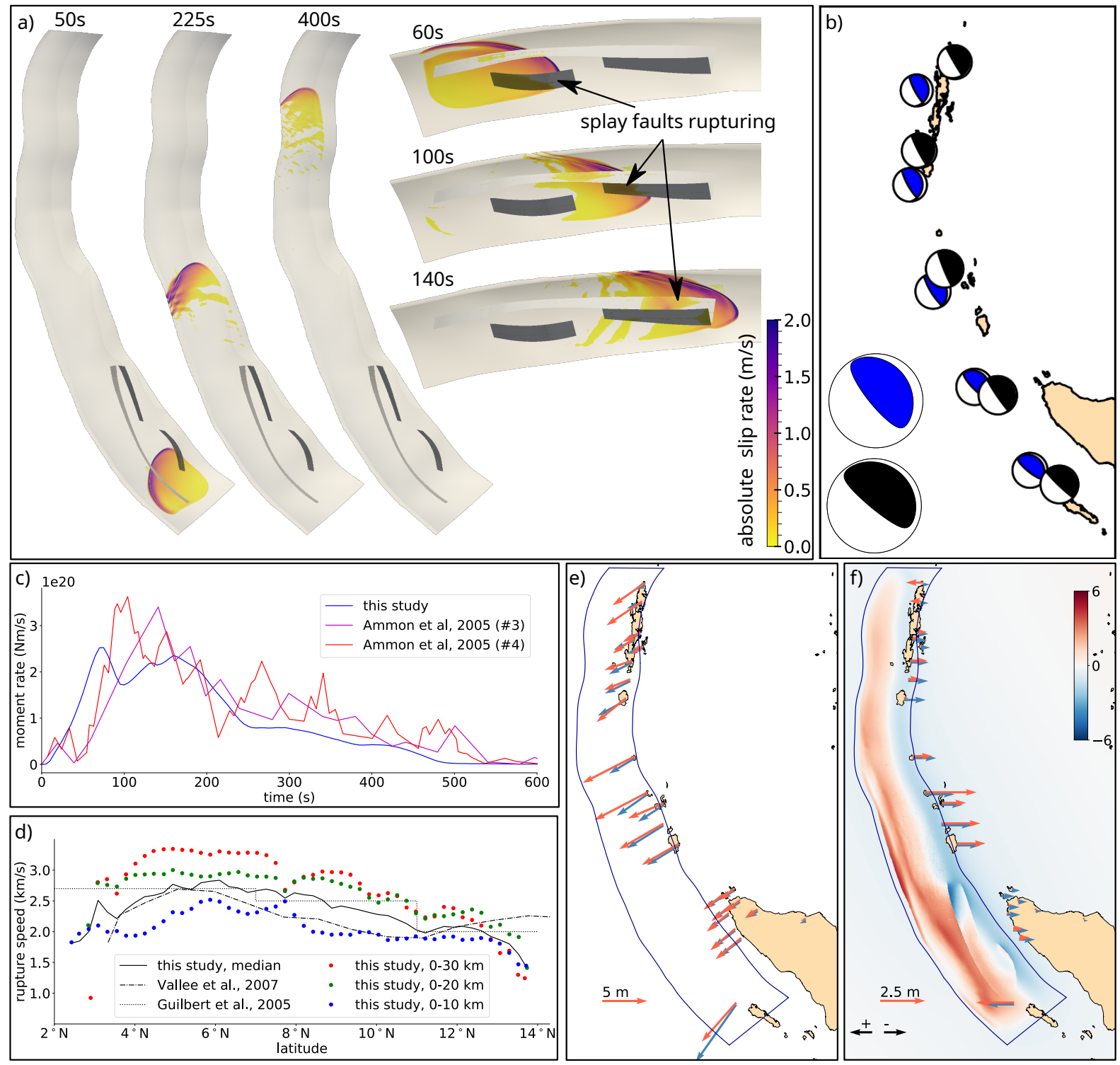

Figure 2: Dynamics and kinematics of the observational constrained dynamic rupture model of the 2004 SumatraAndaman earthquake. (a) Boomerang shaped megathrust slip pulse consisting of multiple rupture fronts. Snapshots of absolute fault particle velocity (slip rate). (b) Moment-tensor representation of the dynamic rupture scenario (blue, large) compared to the moment-tensor representation inferred by USGS (black, large) and comparison of a five point source model derived from the dynamic scenario (blue, small) with a respective solution from teleseismic inversion (21) (black, small). (e) Synthetic moment rate release compared with observational inferences from teleseismics by (17). (f) Along-arc and along-depth variation of rupture speed, compared with inference from Rayleigh waves (50) and from acoustic observations (51). (c) and (d) Comparison of synthetic ground displacements (blue) and geodetic observations (orange). (c) Horizontal ground displacements. (d) Vertical ground displacements. The complete uplift and subsidence resulting from the dynamic rupture scenario (in $\mathrm{m}$ ) is shown in red to blue including noticeable splay faulting signatures. 


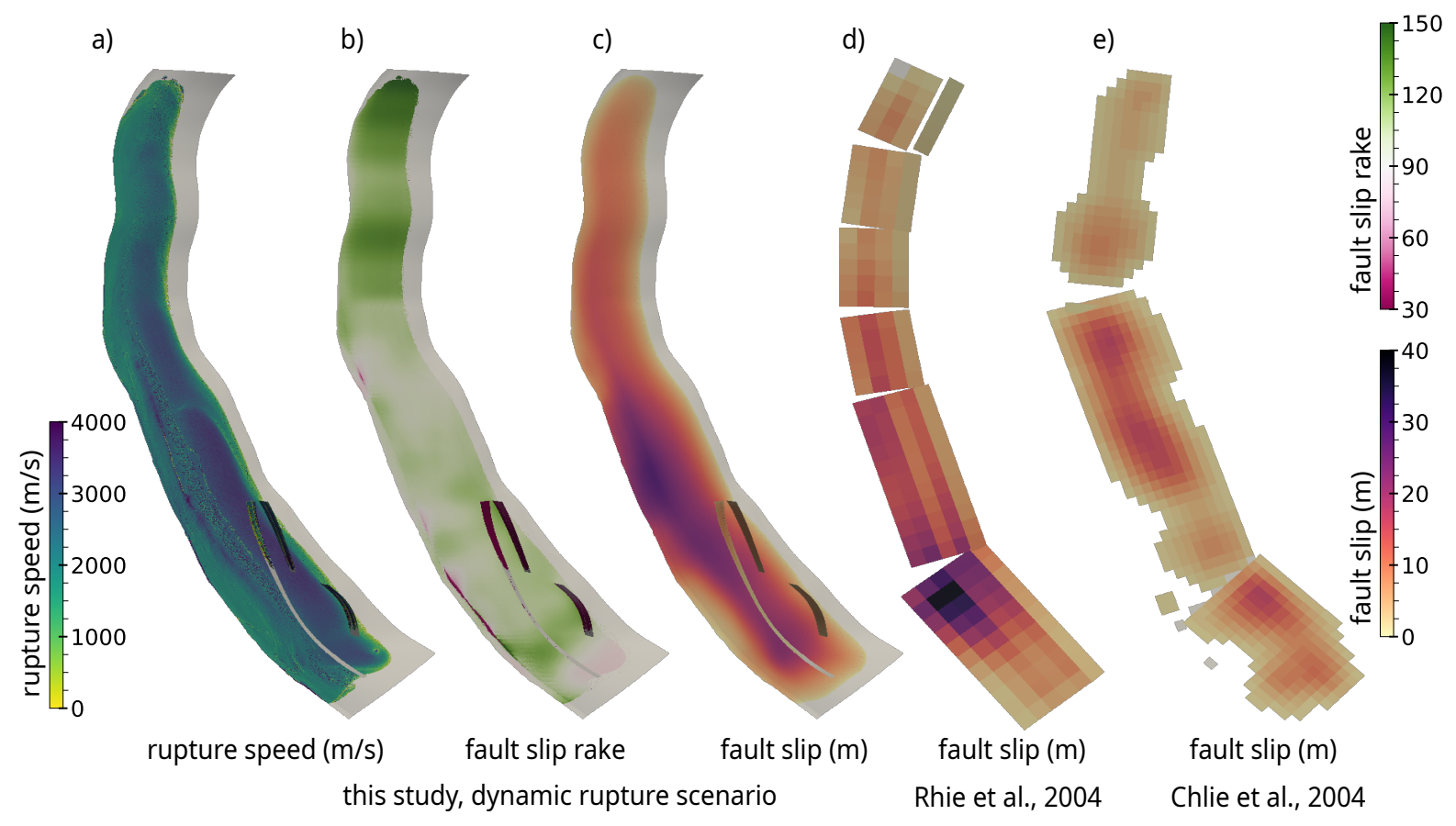

Figure 3: Source properties of the dynamic rupture scenario $(a, b, c)$ and comparison with previously published kinematic models. (a) rupture speed, (b) fault slip rake angle, (c) fault slip, (d) kinematic slip model based on seismological and geodetic data (19) (e) kinematic slip model from geodetic observations (18). 
tively more or less off-fault deformation (see Fig. 4a).In all models, the bulk cohesion is a combination of a depth-dependent term, $C_{1}(z) \sigma_{c}^{\prime}$ with $\sigma_{c}^{\prime}$ the effective confining stress, which accounts for rock strengthening with depth, and a constant term $C_{0}$, which controls localization of off-fault yielding at shallow depth, as detailed in Appendix Sec. "Off-fault plasticity"). In the base dynamic-rupture-tsunami scenario, we assign $C_{0}=1 \mathrm{MPa}$ and $C_{1}(z)=1$, appropriate for partially consolidated sediments (35). Slip to the trench (Fig. 4b) is limited by asymmetric, wide-spread plastic yielding in the shallow part of the accretionary wedge (Fig. 4a). The alternative scenarios result in distinctly different distributions of shallow slip in the upper $15 \mathrm{~km}$ (Fig. 4b). Stronger sediments $\left(C_{0}=10 \mathrm{MPa}\right.$ and $C_{1}(z)=1$ representing lithified sediments entering the trench) cause localized and weak off-fault yielding and fault slip locally exceeds $50 \mathrm{~m}$ at the trench. In contrast, weaker sediments $\left(C_{0}=0.3 \mathrm{MPa}\right.$, $C_{1}(z)=\max \left(1,(z / 15000)^{2}\right)$ and at shallow depth decreased bulk internal friction, representing unconsolidated sediments) prevent near-trench slip, but cause widespread plastic deformation off the megathrust and off the splay faults (see Fig. S4d). Also, the shallow rupture speed in the uppermost $10 \mathrm{~km}$ of this scenario (Fig. S7) is reduced, averaging only $1.8 \mathrm{~km} / \mathrm{s}$, which is close to the characteristic slow speed of tsunami-earthquakes (54).

While all three scenarios vary near the trench, they yield indistinguishable teleseismic (Fig. S2) and geodetic synthetics (Fig. S4). They also are equivalent in terms of macroscopic earthquake kinematics (Fig. S9), which are driven by the deeper portions of rupture. The radiation efficiency of the flat, shallow parts of the megathrust is low. Also, the near-trench region is embedded in low-rigidity sediments and thus contributes little to the total released seismic moment.

We evaluate the dynamic-rupture-tsunami scenarios against geodetic tsunami observations. All three dynamic rupture scenarios source a large-scale tsunami that propagates across the entire simulated domain (see Fig. 4c). The amplitudes and shorter period characteristics of the dynamically sourced tsunami synthetics are sensitive to both fault slip at the trench and off-fault plastic deformation. The tsunami sourced by the base scenario and the stronger-sediment scenario match timing and amplitude of water height anomalies captured by the Jason-1 satellite about 2 hours after the mainshock (see Fig. 4d). The tsunami sourced by the weaker-sediment earthquake scenario featuring pronounced off-fault yielding and no slip to the trench produces tsunami waves amplified by a factor of 

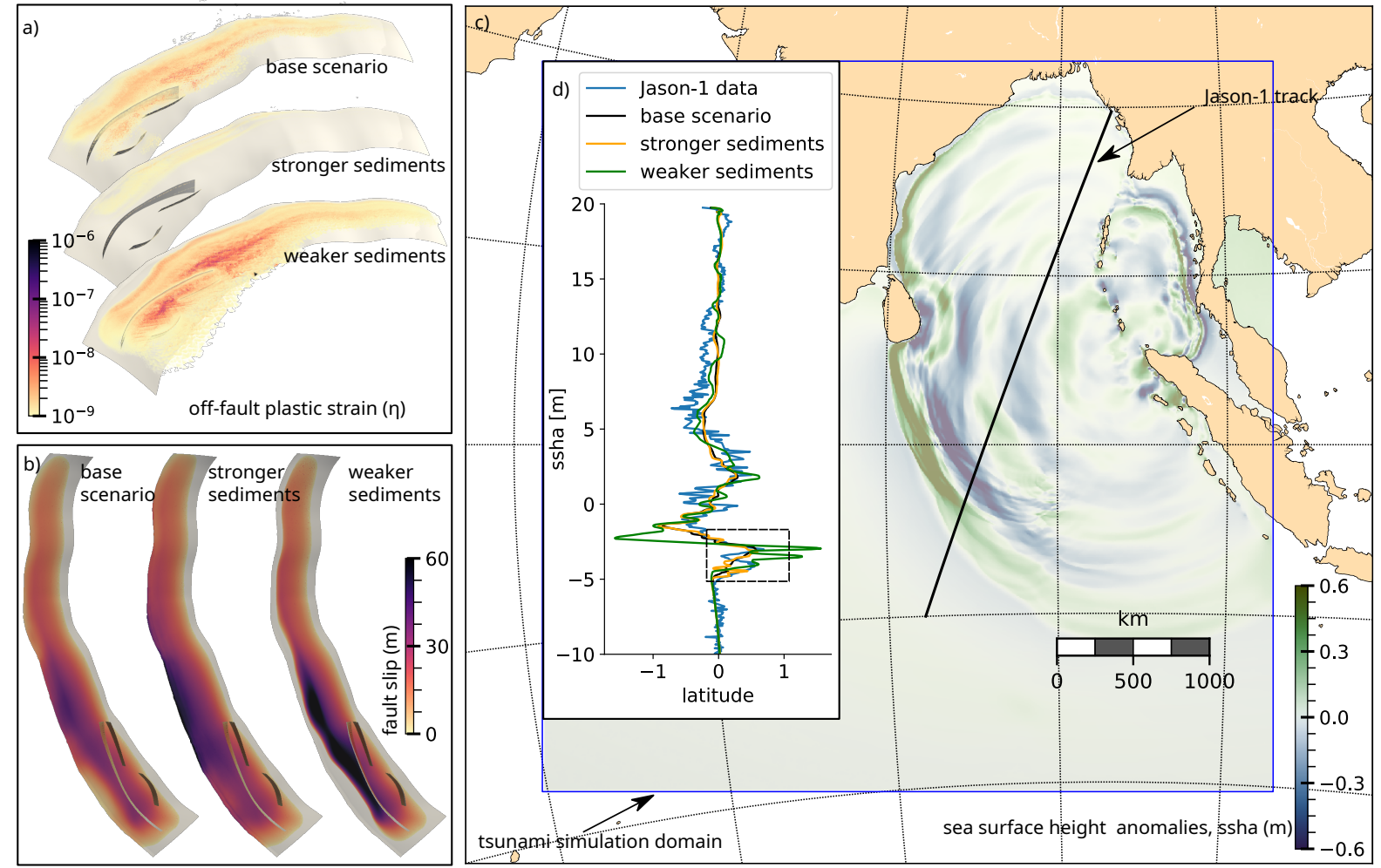

Figure 4: Off-fault yielding and tsunami genesis. a) Off-fault plastic strain accumulated in the base and 2 alternative earthquake scenarios with differing visco-elastic characteristics, yielding stronger or weaker sediments. b) Fault slip (m) of the three scenarios. c) Tsunami induced sea surface height anomalies (ssha) sourced by the base dynamic rupture earthquake scenario at 2 hours simulation time. d) ssha (m) recorded by the Jason- 1 satellite about 2 hours after the mainshock compared with tsunami synthetics sourced by the three earthquake scenarios shown in (b). The dashed black rectangle highlights two short period peaks of the first tsunami wave matched solely by the stronger-sediment scenario.

\section{2 to 3 .}

Only the tsunami sourced by the stronger-sediment earthquake scenario captures the pronounced two-peak characteristic of the first tsunami wave, a feature that is recovered by few of the kinematic models in (27). This reconciles previous stochastic analysis (38) implying that surface faulting in the southern rupture zone best reproduces the double-peak in the altimetry data and is consistent with the inference of lithified sediment in this region $(37,55)$.

We identify key factors controlling megathrust earthquake dynamics and tsunamigenic potential using multiphysics numerical modeling capable of incorporating sophisticated imaging of complex lithological and fault struc- 
ture in combination with a stringent framework to determine earthquake initial conditions. The such-found conditions governing a geometrically complex model of the 2004 Sumatra-Andaman earthquake and Indian Ocean tsunami include elevated fluid pressure and reveal a high friction drop on a statically strong and well-oriented megathrust interface. A simple linear-slip weakening friction law combined with off-fault yielding captures key features of the seismic, geodetic, and tsunami observations in the near- and far-field.

Natural megathrusts vary in additional ways due to local complexities in slab morphology and convergence rates, as well as sediment cover. Our approach yields smoothly varying rupture dynamics and kinematic characteristics, such as fault slip and rupture speed, across the megathrust. While spatial variations in geometric and rheological complexities are found to correlate on length scales of hundreds of meters in 3D imaging (11), smallerscale geometrical complexity of the fault interfaces may produce more heterogeneity in these features, as inferred in some data-driven kinematic models. The subduction interface remains nearly optimally oriented in this model (see Fig. S8) and the variation of absolute prestress magnitudes is small. The variations in regional scale megathrust geometry are counteracted by the observationally constrained variations in the regional driving stresses. This approach can be extended to include further sources of spatio-temporal heterogeneities, which may modulate prestress and thus megathrust rupture dynamics. This can include variations in seismic coupling $(56,57)$, subducted structural features (58), as well as stress changes due to aseismic creep and previous earthquakes $(59,60)$.

Both sediment load entering the subduction channel and lithification of those sediments have been connected to the near-surface behavior and tsunamigenic potential of subduction zones. While high sedimentation has been linked statistically to large earthquakes (61-64), the scenarios we present here emphasize that the strength of these sediments is key. Indeed, we find that depth-dependent rigidity and the amount of off-fault plastic yielding of neartrench rocks are dominant factors controlling earthquake dynamics and tsunami genesis. Specifically, the Bengal fan to the north is associated with increased sediment thickness (65) and a thick layer of lithified sediment has been evidenced in the southern part of the Andaman trench (55). However, the nature and amount of sediments certainly vary along the megathrust. We expect that taking along-arc variations of rigidity and sediment yield strength into account will lead to along-arc variations in shallow rupture dynamics and tsunami genesis (45). 
The physics-based numerical models presented here reveal relationships between megathrust fault geometries, tectonic loading, rigidity variations with depth and sediment strength with megathrust hazard, and emphasize the importance of regional-scale structural heterogeneity for earthquake dynamics and tsunami genesis. Novel seafloor observatories (66) have the potential to provide detailed images of near-trench regions world-wide. Our computational capabilities render possible the incorporation of present and emerging high-resolution observations into dynamic-rupture-tsunami models. We have demonstrated for the Great Sumatra-Andaman earthquake and tsunami that dominant factors controlling megathrust hazards can be identified, which, in principle can be applied to subduction zones globally. Incorporating smaller scale heterogeneities and observational uncertainties into our models will enhance both scenario focused modeling and physics-based probabilistic hazard assessment of the future.

\section{References}

1. Bilek, S. L. \& Lay, T. Rigidity variations with depth along interplate megathrust faults in subduction zones. Nature 400, 443-446 (1999).

2. Tobin, H. J. \& Saffer, D. M. Elevated fluid pressure and extreme mechanical weakness of a plate boundary thrust, Nankai Trough subduction zone. Geology 37, 679-682 (2009).

3. Noda, H. \& Lapusta, N. Stable creeping fault segments can become destructive as a result of dynamic weakening. Nature 493, 518-521 (2013).

4. Hardebeck, J. L. Stress orientations in subduction zones and the strength of subduction megathrust faults. Science 349, 1213-1216 (2015).

5. Sallarès, V. \& Ranero, C. R. Upper-plate rigidity determines depth-varying rupture behaviour of megathrust earthquakes. Nature 576, 96-101 (2019).

6. Fujiwara, T. et al. The 2011 Tohoku-Oki Earthquake: Displacement Reaching the Trench Axis. Science 334, 1240-1240 (2011). 
7. Nanayama, F. et al. Unusually large earthquakes inferred from tsunami deposits along the Kuril trench. Nature 424, 660-663 (2003).

8. Cummins, P. R. \& Kaneda, Y. Possible splay fault slip during the 1946 Nankai earthquake. Geophysical Research Letters 27, 2725-2728 (2000).

9. Lay, T. et al. Depth-varying rupture properties of subduction zone megathrust faults. Journal of Geophysical Research: Solid Earth 117 (2012).

10. Seno, T. The 21 September, 1999 Chi-Chi Earthquake in Taiwan: Implications for Tsunami Earthquakes. Terrestrial, Atmospheric and Oceanic Sciences 11, 701 (2000).

11. Kirkpatrick, J. D. et al. Subduction megathrust heterogeneity characterized from $3 \mathrm{~d}$ seismic data. Nature Geoscience 1-6 (2020).

12. Ruff, L. \& Kanamori, H. Seismicity and the subduction process. Physics of the Earth and Planetary interiors 23, 240-252 (1980).

13. Rikitake, T. Recurrence of great earthquakes at subduction zones. Tectonophysics 35, 335-362 (1976).

14. Uyeda, S. \& Kanamori, H. Back-arc opening and the mode of subduction. Journal of Geophysical Research: Solid Earth 84, 1049-1061 (1979).

15. Müller, R. D., Roest, W. R., Royer, J.-Y., Gahagan, L. M. \& Sclater, J. G. Digital isochrons of the world's ocean floor. Journal of Geophysical Research: Solid Earth 102, 3211-3214 (1997).

16. Curray, J. R. Tectonics and history of the Andaman Sea region. Journal of Asian Earth Sciences 25, 187-232 (2005).

17. Ammon, C. J. et al. Rupture Process of the 2004 Sumatra-Andaman Earthquake. Science 308, 1133-1139 (2005). 
18. Chlieh, M. et al. Coseismic Slip and Afterslip of the Great Mw 9.15 Sumatra-Andaman Earthquake of 2004. Bulletin of the Seismological Society of America 97, S152-S173 (2007).

19. Rhie, J., Dreger, D., Bürgmann, R. \& Romanowicz, B. Slip of the 2004 Sumatra-Andaman Earthquake from Joint Inversion of Long-Period Global Seismic Waveforms and gps Static Offsets. Bulletin of the Seismological Society of America 97, S115-S127 (2007).

20. Stein, S. \& Okal, E. A. Speed and size of the Sumatra earthquake. Nature 434, 581-582 (2005).

21. Tsai, V. C., Nettles, M., Ekström, G. \& Dziewonski, A. M. Multiple CMT source analysis of the 2004 Sumatra earthquake. Geophysical Research Letters 32 (2005).

22. de Linage, C. et al. Separation of coseismic and postseismic gravity changes for the 2004 Sumatra-Andaman earthquake from $4.6 \mathrm{yr}$ of GRACE observations and modelling of the coseismic change by normal-modes summation. Geophysical Journal International 176, 695-714 (2009).

23. Fujii, Y. \& Satake, K. Tsunami Source of the 2004 Sumatra-Andaman Earthquake Inferred from Tide Gauge and Satellite Data. Bulletin of the Seismological Society of America 97, S192-S207 (2007).

24. de Groot-Hedlin, C. D. Estimation of the rupture length and velocity of the Great Sumatra earthquake of Dec 26, 2004 using hydroacoustic signals. Geophysical Research Letters 32, L11303 (2005).

25. Ishii, M., Shearer, P. M., Houston, H. \& Vidale, J. E. Extent, duration and speed of the 2004 Sumatra-Andaman earthquake imaged by the Hi-Net array. Nature 435, 933 (2005).

26. Shearer, P. \& Bürgmann, R. Lessons Learned from the 2004 Sumatra-Andaman Megathrust Rupture (2010).

27. Poisson, B., Oliveros, C. \& Pedreros, R. Is there a best source model of the Sumatra 2004 earthquake for simulating the consecutive tsunami? Geophysical Journal International 185, 1365-1378 (2011).

28. Borrero, J. C. Field Data and Satellite Imagery of Tsunami Effects in Banda Aceh. Science 308, 1596-1596 (2005). 
29. Sibuet, J. et al. 26th December 2004 great Sumatra-Andaman earthquake: Co-seismic and post-seismic motions in northern Sumatra. Earth and Planetary Science Letters 263, 88-103 (2007).

30. Chauhan, A. P. S. et al. Seismic imaging of forearc backthrusts at northern Sumatra subduction zone. Geophysical Journal International 179, 1772-1780 (2009).

31. Singh, S. C. et al. Seismic evidence for broken oceanic crust in the 2004 Sumatra earthquake epicentral region. Nature Geoscience 1, 777-781 (2008).

32. DeDontney, N. \& Rice, J. R. Tsunami Wave Analysis and Possibility of Splay Fault Rupture During the 2004 Indian Ocean Earthquake. Pure and Applied Geophysics 169, 1707-1735 (2012).

33. Waldhauser, F., Schaff, D. P., Diehl, T. \& Engdahl, E. R. Splay faults imaged by fluid-driven aftershocks of the 2004 Mw 9.2 Sumatra-Andaman earthquake. Geology 40, 243-246 (2012).

34. Geersen, J., McNeill, L., Henstock, T. J. \& Gaedicke, C. The 2004 Aceh-Andaman Earthquake: Early clay dehydration controls shallow seismic rupture: Shallow Rupture off Northern Sumatra. Geochemistry, Geophysics, Geosystems 14, 3315-3323 (2013).

35. Gulick, S. P. S. et al. Updip rupture of the 2004 Sumatra earthquake extended by thick indurated sediments. Nature Geoscience 4, 453-456 (2011).

36. Qin, Y. \& Singh, S. C. Seismic evidence of a two-layer lithospheric deformation in the Indian Ocean. Nature Communications 6, 8298 (2015).

37. Hüpers, A. et al. Release of mineral-bound water prior to subduction tied to shallow seismogenic slip off Sumatra. Science 356, 841-844 (2017).

38. Geist, E. L., Titov, V. V., Arcas, D., Pollitz, F. F. \& Bilek, S. L. Implications of the 26 December 2004 Sumatra-Andaman Earthquake on Tsunami Forecast and Assessment Models for Great Subduction-Zone Earthquakes. Bulletin of the Seismological Society of America 97, S249-S270 (2007). 
39. Olsen, K. B., Madariaga, R. \& Archuleta, R. J. Three-Dimensional Dynamic Simulation of the 1992 Landers Earthquake. Science 278, 834-838 (1997).

40. Douilly, R., Aochi, H., Calais, E. \& Freed, A. M. Three-dimensional dynamic rupture simulations across interacting faults: The Mw7.0, 2010, Haiti earthquake. Journal of Geophysical Research: Solid Earth 120, $1108-1128(2015)$.

41. Kyriakopoulos, C., Oglesby, D. D., Funning, G. J. \& Ryan, K. J. Dynamic Rupture Modeling of the $M$ 7.2 2010 El Mayor-Cucapah Earthquake: Comparison With a Geodetic Model. Journal of Geophysical Research: Solid Earth 122, 10,263-10,279 (2017).

42. Wollherr, S., Gabriel, A. \& Mai, P. M. Landers 1992 "Reloaded”: Integrative Dynamic Earthquake Rupture Modeling. Journal of Geophysical Research: Solid Earth (2019).

43. Ulrich, T., Gabriel, A.-A., Ampuero, J.-P. \& Xu, W. Dynamic viability of the 2016 Mw 7.8 Kaikōura earthquake cascade on weak crustal faults. Nature Communications 10, 1213 (2019).

44. Ulrich, T. et al. Coupled, Physics-Based Modeling Reveals Earthquake Displacements are Critical to the 2018 Palu, Sulawesi Tsunami. Pure and Applied Geophysics (2019).

45. Ma, S. \& Nie, S. Dynamic Wedge Failure and Along-Arc Variations of Tsunamigenesis in the Japan Trench Margin. Geophysical Research Letters 46, 8782-8790 (2019).

46. McCaffrey, R. The Tectonic Framework of the Sumatran Subduction Zone (2009).

47. Hardebeck, J. L. Coseismic and postseismic stress rotations due to great subduction zone earthquakes. Geophysical Research Letters 39 (2012).

48. Gahalaut, V. K. \& Gahalaut, K. Burma plate motion. Journal of Geophysical Research 112, B10402 (2007). 
49. Duputel, Z., Rivera, L., Kanamori, H. \& Hayes, G. W phase source inversion for moderate to large earthquakes (1990-2010): W phase inversion for Mw $\geq 6.0$ earthquakes. Geophysical Journal International 189, 1125-1147 (2012).

50. Vallee, M. Rupture Properties of the Giant Sumatra Earthquake Imaged by Empirical Green's Function Analysis. Bulletin of the Seismological Society of America 97, S103-S114 (2007).

51. Guilbert, J. Use of hydroacoustic and seismic arrays to observe rupture propagation and source extent of the $M_{w}=9.0$ Sumatra earthquake. Geophysical Research Letters 32, L15310 (2005).

52. Sladen, A. \& Trevisan, J. Shallow megathrust earthquake ruptures betrayed by their outer-trench aftershocks signature. Earth and Planetary Science Letters 483, 105-113 (2018).

53. Kozdon, J. E. \& Dunham, E. M. Rupture to the Trench: Dynamic Rupture Simulations of the 11 March 2011 Tohoku Earthquake. Bulletin of the Seismological Society of America 103, 1275-1289 (2013).

54. Kanamori, H. Mechanism of tsunami earthquakes. Physics of the Earth and Planetary Interiors 6, 346-359 (1972).

55. Qin, Y. \& Singh, S. C. Detailed seismic velocity of the incoming subducting sediments in the 2004 great Sumatra earthquake rupture zone from full waveform inversion of long offset seismic data: Seismic Velocity of Subducting Sediments. Geophysical Research Letters 44, 3090-3099 (2017).

56. Hardebeck, J. L. \& Loveless, J. P. Creeping subduction zones are weaker than locked subduction zones. Nature Geoscience 11, 60-64 (2018).

57. Yang, H., Yao, S., He, B. \& Newman, A. V. Earthquake rupture dependence on hypocentral location along the Nicoya Peninsula subduction megathrust. Earth and Planetary Science Letters 520, 10-17 (2019).

58. Singh, S. C. et al. Aseismic zone and earthquake segmentation associated with a deep subducted seamount in Sumatra. Nature Geoscience 4, 308-311 (2011). 
59. Aochi, H. \& Ide, S. Conceptual multi-scale dynamic rupture model for the 2011 off the Pacific coast of Tohoku Earthquake. Earth, Planets and Space 63, 761-765 (2011).

60. Ide, S. \& Aochi, H. Historical seismicity and dynamic rupture process of the 2011 Tohoku-Oki earthquake. Tectonophysics 600, 1-13 (2013).

61. Seno, T. Determination of the pore fluid pressure ratio at seismogenic megathrusts in subduction zones: Implications for strength of asperities and Andean-type mountain building. Journal of Geophysical Research 114, B05405 (2009).

62. Seno, T. Subducted sediment thickness and $M_{w} 9$ earthquakes: Subducted Sediment Thickness and $M_{w}$ 9. Journal of Geophysical Research: Solid Earth 122, 470-491 (2017).

63. Heuret, A., Conrad, C. P., Funiciello, F., Lallemand, S. \& Sandri, L. Relation between subduction megathrust earthquakes, trench sediment thickness and upper plate strain. Geophysical Research Letters 39 (2012).

64. Scholl, D. W. et al. Great (Mw8.0) megathrust earthquakes and the subduction of excess sediment and bathymetrically smooth seafloor. Geosphere 11, 236-265 (2015).

65. Subarya, C. et al. Plate-boundary deformation associated with the great Sumatra-Andaman earthquake. Nature 440, 46 (2006).

66. Nishikawa, T. et al. The slow earthquake spectrum in the Japan Trench illuminated by the S-net seafloor observatories. Science 365, 808-813 (2019).

67. Vater, S., Beisiegel, N. \& Behrens, J. A limiter-based well-balanced discontinuous Galerkin method for shallow-water flows with wetting and drying: Triangular grids. International Journal for Numerical Methods in Fluids (2019).

68. Behrens, J. et al. amatos: Parallel adaptive mesh generator for atmospheric and oceanic simulation. Ocean Modelling 10, 171-183 (2005). 
69. Oeser, J., Bunge, H.-P. \& Mohr, M. Cluster design in the earth sciences: Tethys. In International conference on high performance computing and communications, 31-40 (Springer, 2006).

70. Laske, G., Masters, G., Ma, Z. \& Pasyanos, M. Update on crust1. 0-a 1-degree global model of earth's crust. In Geophys. Res. Abstr, vol. 15, 2658 (EGU General Assembly Vienna, Austria, 2013).

71. Weatherall, P. et al. A new digital bathymetric model of the world's oceans. Earth and Space Science 2, $331-345$ (2015).

72. Lay, T. et al. Depth-varying rupture properties of subduction zone megathrust faults. Journal of Geophysical Research: Solid Earth 117 (2012).

73. Hayes, G. P., Wald, D. J. \& Johnson, R. L. Slab1.0: A three-dimensional model of global subduction zone geometries. Journal of Geophysical Research: Solid Earth 117 (2012).

74. Banerjee, P., Pollitz, F., Nagarajan, B. \& Burgmann, R. Coseismic Slip Distributions of the 26 December 2004 Sumatra-Andaman and 28 March 2005 Nias Earthquakes from GPS Static Offsets. Bulletin of the Seismological Society of America 97, S86-S102 (2007).

75. Lin, J.-Y., Le Pichon, X., Rangin, C., Sibuet, J.-C. \& Maury, T. Spatial aftershock distribution of the 26 December 2004 great Sumatra-Andaman earthquake in the northern Sumatra area. Geochemistry, Geophysics, Geosystems 10 (2009).

76. Aochi, H. \& Madariaga, R. The 1999 Izmit, Turkey, earthquake: Nonplanar fault structure, dynamic rupture process, and strong ground motion. Bulletin of the Seismological Society of America 93, 1249-1266 (2003).

77. DeMets, C., Gordon, R. G., Argus, D. F. \& Stein, S. Effect of recent revisions to the geomagnetic reversal time scale on estimates of current plate motions. Geophysical Research Letters 21, 2191-2194 (1994).

78. Hardebeck, J. L. \& Hauksson, E. Crustal stress field in southern California and its implications for fault mechanics. Journal of Geophysical Research: Solid Earth 106, 21859-21882 (2001). 
79. Byerlee, J. Friction of rocks. Pure and Applied Geophysics 116, 615-626 (1978).

80. Melgar, D. \& Hayes, G. P. Systematic Observations of the Slip Pulse Properties of Large Earthquake Ruptures. Geophysical Research Letters 44, 9691-9698 (2017).

81. Ma, S. A self-consistent mechanism for slow dynamic deformation and tsunami generation for earthquakes in the shallow subduction zone. Geophysical Research Letters 39 (2012).

82. Dumbser, M. \& Käser, M. An arbitrary high-order discontinuous Galerkin method for elastic waves on unstructured meshes - II. the three-dimensional isotropic case. Geophysical Journal International 167, 319336 (2006).

83. Pelties, C., de la Puente, J., Ampuero, J.-P., Brietzke, G. B. \& Käser, M. Three-dimensional dynamic rupture simulation with a high-order discontinuous Galerkin method on unstructured tetrahedral meshes. Journal of Geophysical Research: Solid Earth 117 (2012).

84. Uphoff, C. et al. Extreme scale multi-physics simulations of the tsunamigenic 2004 sumatra megathrust earthquake. In Proceedings of the International Conference for High Performance Computing, Networking, Storage and Analysis, SC 2017 (2017).

85. Breuer, A. et al. Sustained Petascale Performance of Seismic Simulations with SeisSol on SuperMUC. In Supercomputing. ISC 2014. Lecture Notes in Computer Science, vol 8488, 1-18 (Springer, Cham, 2014).

86. Heinecke, A. et al. Petascale High Order Dynamic Rupture Earthquake Simulations on Heterogeneous Supercomputers. In SC14: International Conference for High Performance Computing, Networking, Storage and Analysis, 3-14 (IEEE, New Orleans, LA, USA, 2014).

87. Rettenberger, S., Meister, O., Bader, M. \& Gabriel, A.-A. Asagi: A parallel server for adaptive geoinformation. In Proceedings of the Exascale Applications and Software Conference 2016, EASC '16, 2:1-2:9 (ACM, New York, NY, USA, 2016). 
88. Wollherr, S., Gabriel, A.-A. \& Uphoff, C. Off-fault plasticity in three-dimensional dynamic rupture simulations using a modal Discontinuous Galerkin method on unstructured meshes: implementation, verification and application. Geophysical Journal International 214, 1556-1584 (2018).

89. Pelties, C., Gabriel, A.-A. \& Ampuero, J.-P. Verification of an ADER-DG method for complex dynamic rupture problems. Geoscientific Model Development 7, 847-866 (2014).

90. Harris, R. A. et al. Verifying a computational method for predicting extreme ground motion. Seismological Research Letters 82, 638-644 (2011).

91. Harris, R. A. et al. A Suite of Exercises for Verifying Dynamic Earthquake Rupture Codes. Seismological Research Letters 89, 1146-1162 (2018).

92. Day, S. M., Dalguer, L. A., Lapusta, N. \& Liu, Y. Comparison of finite difference and boundary integral solutions to three-dimensional spontaneous rupture. Journal of Geophysical Research 110, B12307 (2005).

93. Meister, O., Rahnema, K. \& Bader, M. Parallel, memory efficient adaptive mesh refinement on structured triangular meshes with billions of grid cells. ACM Transactions on Mathematical Software 43, 19:1-19:27 (2016).

94. Cockburn, B. \& Shu, C.-W. The Runge-Kutta discontinuous Galerkin method for conservation laws V: Multidimensional systems. Journal of Computational Physics 141, 199-224 (1998).

95. Giraldo, F. X. \& Warburton, T. A high-order triangular discontinuous galerkin oceanic shallow water model. International Journal for Numerical Methods in Fluids 56, 899-925 (2008).

96. Honal, C. \& Rannabauer, L. Comparing the numerical results in [Vater S., N. Beisiegel, and J. Behrens, 2019] to results produced by the FLASH implementation in Samoa2 (2020). URL https: / zenodo. org/record/3803665. Version Number: 0.1 type: dataset.

97. Tanioka, Y. \& Satake, K. Tsunami generation by horizontal displacement of ocean bottom. Geophysical Research Letters 23, 861-864 (1996). 
98. Saito, T., Baba, T., Inazu, D., Takemura, S. \& Fukuyama, E. Synthesizing sea surface height change including seismic waves and tsunami using a dynamic rupture scenario of anticipated Nankai trough earthquakes. Tectonophysics 228166 (2019).

99. Lotto, G. C., Jeppson, T. N. \& Dunham, E. M. Fully coupled simulations of megathrust earthquakes and tsunamis in the Japan Trench, Nankai Trough, and Cascadia Subduction Zone. Pure and Applied Geophysics $1-33$ (2018).

100. Krenz, L. et al. T52C-09: Elastic-Acoustic Coupling for 3D Tsunamigenic Earthquake Simulations with ADER-DG on Unstructured Tetrahedral Meshes. In AGU Fall Meeting 2019 (San Francisco, 2019). URL https://ui.adsabs.harvard.edu/abs/2019AGUFM.T52C..09K/abstract.

101. Okuda, T. \& Ide, S. Hierarchical rupture growth evidenced by the initial seismic waveforms. Nature Communications 9, 3714 (2018).

102. Gupta, S., Borah, K. \& Saha, G. Continental like crust beneath the Andaman Island through joint inversion of receiver function and surface wave from ambient seismic noise. Tectonophysics 687, 129-138 (2016).

103. Hayes, G. P. et al. Slab2, a comprehensive subduction zone geometry model. Science 362, 58-61 (2018).

104. Bletery, Q., Sladen, A., Jiang, J. \& Simons, M. A Bayesian source model for the 2004 great SumatraAndaman earthquake. Journal of Geophysical Research: Solid Earth 121, 5116-5135 (2016).

105. Krischer, L. et al. On-demand custom broadband synthetic seismograms. Seismological Research Letters 88, 1127-1140 (2017).

\section{Acknowledgments}

We thank Leonhard Rannabauer for software support for the tsunami simulations using sam(oa) ${ }^{2}$. We thank Stefan Vater for verifying a preliminary tsunami scenario with the software Stormflash (67), which is based on the amatos adaptive mesh generator for atmospheric and oceanic simulations (68). We thank Stephanie Wollherr, Carsten 
Uphoff, Michael Bader, Sebastian Rettenberger, and Jörn Behrens for fruitful discussion. We thank Mohamed Chlieh for providing his kinematic model of the Sumatra-Andaman event.

\section{Funding}

The authors acknowledge funding from the Volkswagen Foundation (project "ASCETE", grant no. 88479), the European Union's Horizon 2020 research and innovation programme (ChEESE project, grant agreement No. 823844; TEAR ERC Starting grant no. 852992), the German Research Foundation (DFG) (projects KA 2281/4-1, GA 2465/2-1, GA 2465/3-1), by KAUST-CRG (GAST, grant no. ORS-2016-CRG5-3027 and FRAGEN, grant no. ORS-2017-CRG6 3389.02), by KONWIHR - the Bavarian Competence Network for Technical and Scientific High Performance Computing (project NewWave), and by BayLat - the Bavarian University Centre for Latin America. Computing resources were provided by the Institute of Geophysics of LMU Munich (69) and the Leibniz Supercomputing Centre (LRZ, projects no. h019z, pr63qo, and pr45fi).

\section{Author contributions}

Modeling was conducted by T.U. under the supervision of A.-A. G.. A.-A. G. initiated the project. E.H.M. designed the splay faults model. The manuscript was written jointly by T.U., A.-A. G. and E.H.M..

\section{Competing interests}

The authors declare no competing interests and no conflict of interests.

\section{Data and materials availability}

The authors declare that all data supporting the findings of this study are available within the paper and its Methods section. In particular, all data required to reproduce the earthquake scenario can be downloaded from https: //syncandshare.lrz.de/getlink/fiXD3hkMGBoMR8mTW99aqdy5/. We provide a detailed readme file summarizing the data and data formats provided. We use the following projection: WGS 84 / UTM Mercator 46N (EPSG:32646). We use SeisSol, commit b553760, available on Github. The procedure to download, compile, and run SeisSol is described in its documentation (https://seissol.readthedocs.io). All 
data required to reproduce the tsunami scenarios can be downloaded from https://syncandshare. lrz. de/public?folderID=MktLbkVxRUwzZzNBaFJLVFNEZ2Nw. We use the sam(oa) ${ }^{2}$, commit a298e2b1, available on GitLab. Sea surface height anomalies derived from the Jason-1 data record are available at ftp: //podaac-ftp.jpl.nasa.gov/allData/jason1/L2/j1_ssha/c109/.

\section{List of Supplementary Materials}

Methods and Appendix

Supplementary Text

Figs. S1 to S9

Table S1

References (70-102) 


\section{Methods}

\section{Regional lithological structure}

We construct a 3D subsurface computational model of the Sumatra-Andaman region to capture spatial variations of lithology and seismic rock properties. The model incorporates a complex subduction interface, large-scale layers varying in thickness (70), and topography and bathymetry data (71) (see Appendix Sect. "3D velocity model"). We add a $6 \mathrm{~km}$ wide layer to the $1 \mathrm{D}$ velocity structure above the subduction interface. Within this approximated subduction channel and the uppermost layer of the oceanic crust, strong along-depth rigidity variations are incorporated (Fig. 1e), as globally inferred from earthquake rupture duration $(1,72)$ and from $V_{p}$ velocity models (5). We increase rigidity piecewise linearly with depth from 10 to $43 \mathrm{MPa}$, thus accounting for softer rocks at shallow depth, including materials scraped off the oceanic crust and younger deposits (Fig. 1e).

\section{Fault geometry}

We construct a non-planar model of the subduction interface and possible splay faults that may have ruptured during the 2004 earthquake (Figs.1c and 2a). The slab interface is based on the geometry of Slab 1.0 (73), which is then extended to the trench and to the north, to cover the full span of the 2004 rupture. Evidence that splay faults slipped coseismically during the 2004 event stems from large tsunami run-ups observed in Aceh province in the near-source region (e.g., (74)), high reflectivity in shallow seismic reflection data (31), and aftershocks $(33,75)$, the double peak in the tsunami waves recorded by the Jason-1 satellite (32), alongside other observations (e.g., (29)). We add one long forethrust dipping $45^{\circ}$ landward and two backthrust faults dipping $45^{\circ}$ trenchward. Each extends from their inferred trace to the megathrust interface. The forethrust unifies the Upper Splay Fault mapped by (29) and the splay fault suggested by (32). The northern backthrust is mapped from seismic reflection data by (29) and (30) and the southern backthrust is identified by (31) from seismic reflection data. The true extent of these faults are not known; mapped lengths are restricted to the area of data coverage. 


\section{Stress state and fault friction}

The stresses acting on faults and their strength, which are key initial conditions of dynamic rupture models, are poorly known. Laboratory experiments offer insight on frictional strength parameters, but extrapolating these results to a natural scale is complicated. We introduce new procedures to constrain these parameters from stress inversion results (47), including the inference of coseismic rotation of the principal stress axes $(4,47)$.

\section{Principal stress orientations}

In line with (47)'s results, we apply a non-Andersonian initial stress field that features a shallowly plunging maximum compressive stress axis $\left(\sigma_{1}\right)$, a near-horizontal intermediate stress axis $\left(\sigma_{2}\right)$, and a steeply plunging minimum principal stress $\left(\sigma_{3}\right), \sigma_{1}$ plunges at $22^{\circ}$, which optimally stresses a fault dipping $8^{\circ}$.

We align stress inversion and geodetic observations in choosing the $\sigma_{1}$ orientation. The model accounts for the inferred clockwise rotation of $\sigma_{1}$ from $309^{\circ}$ in the South to $330^{\circ}$ in the North (47), with a linear transition over $2^{\circ}$ near $5^{\circ}$ latitude (see Fig. 1a). This leads to synthetic displacements with orientations in overall agreement with geodetic observations.

\section{Principal stress magnitudes}

The principal stress magnitudes are systematically constrained based on seismo-tectonic observations, fault fluid pressurization, and the Mohr-Coulomb theory of frictional failure.

Rupture dynamics are in their general sense governed by the stress drop and the fault strength. These are constrained by the effective confining stress, the fault friction drop $\mu_{s}-\mu_{d}$ (where $\mu_{s}$ and $\mu_{d}$ are the static and dynamic friction coefficients, respectively) and the relative prestress ratio $R_{0}$. The latter is defined as the ratio of prestress over strength drop (e.g., (76)):

$$
R=\left(\tau_{0}-\mu_{d} \sigma_{n}\right) /\left(\left(\mu_{s}-\mu_{d}\right) \sigma_{n}\right)
$$

where $\tau_{0}$ and $\sigma_{n}$ are the initial shear and normal tractions on a fault plane. $R_{0}$ is the maximum value of $R$, associated with a virtual, optimally-oriented fault plane. 
We assume lithostatic confining pressure,

$$
\sigma_{c}(z)=\int_{0}^{z} \rho\left(z_{i}\right) g z_{i} d z_{i}
$$

and a near-lithostatic fluid pressure, $P_{f}=0.974 \sigma_{c}$, to ensure a realistic stress drop. The resulting effective confining stress increases with depth with a gradient of $\approx 1 \mathrm{MPa} / \mathrm{km}$. From $25-45 \mathrm{~km}$ depth, we taper the deviatoric stresses to zero to represent the transition from a brittle to a ductile regime.

We account for along-arc variations in convergence rate by varying the initial stress along-strike of the megathrust. Observations by (47) suggest that the strain accumulated since the last great earthquake, inferred using along-arc variations in convergence rate, is consistent with the along-arc variation in slip inferred for the 2004 earthquake, which is characterized by more slip in the south than in the north.

We modulate $R_{0}$ by the convergence rate inferred from rigid plate tectonics considerations, using the Euler pole inferred by (48) (see Fig. 1b). This modulation is applied only above $6^{\circ}$ North. Our choice of a constant $R_{0}=0.65$ below this latitude is an approximation to account for the effect of internal deformation of the sliver plate to the south (77) and is constrained by the magnitude of the observed coseismic displacements.

\section{Coseismic stress rotation to constrain fault friction}

The inference of coseismic rotation of the principal stress axes (see Fig. 1c) during the 2004 earthquake $(4,47)$ constrains the ratio of the stress drop over the prestress. A significant principal stress rotation indicates that the stress drop is large enough to change the deviatoric background stress (e.g., (78)), that is the prestress and the stress drop are of the same order. This can lead to a sudden switch of orientation of principal axes of stress, as suggested by the occurrence of normal faulting following megathrust earthquakes $(4,47)$.

We estimate the average stress drop $d \tau$ in the dynamic rupture model as

$$
d \tau \sim\left(\mu_{s}-\mu_{d}\right) R_{0}\left(\sigma_{c}-P_{f}\right)
$$

We define $\xi$ as the ratio of residual shear traction over prestress to get

$$
\xi \sim \frac{\mu_{d}}{\left(\mu_{s}-\mu_{d}\right) R_{0}+\mu_{d}}
$$


which can be written as

$$
\mu_{d} \sim \frac{\mu_{s}}{(1-\xi) /\left(R_{0} \xi\right)+1}
$$

Eq. 5 relates $\mu_{d}$ to $\mu_{s}$ and $R_{0}$. Assuming a static friction value of $\mu_{s}=0.6$ (79), a ratio of residual shear traction over prestress of $\xi=0.4$, as inferred in the southern part of the rupture (47)), and a ratio of prestress over strength drop of $R_{0}=0.65$, yields $\mu_{d}=0.18$. Based on these considerations, we use a linear slip weakening friction law setting $\mu_{s}=0.6, \mu_{d}=0.2$ and $D_{c}=2.5 \mathrm{~m}$. The relatively large $D_{c}$ allows recovering the northern rupture arrest, as well as an average rupture speed comparable with published inferences (see Fig 2d). It leads to a wide process zone in our model, which may reflect the larger slip pulse width associated with large megathrust earthquakes (e.g., (80)).

\section{Earthquake computational model}

Computational earthquake models that are able to account for the curved thrust interface and splay fault networks intersecting with bathymetry, the narrow accretionary wedge, and the complex lithology of subduction zones are challenging. Off-fault yielding processes, which can significantly modulate fault slip near the trench (e.g., $(45,81))$, pose additional computational demands. These challenges are addressed using the SeisSol software package (e.g., (82-84)), which solves the nonlinear coupled problem of spontaneous frictional failure across prescribed fault surfaces, seismic wave propagation, and (visco-)plastic Drucker-Prager off-fault damage (e.g., (42)).

SeisSol is based on an Arbitrary high-order accurate DERivative Discontinuous Galerkin method (ADERDG, (82)) and solves the seismic wave equations with high-order accuracy in space and time. SeisSol uses fully non-uniform, adaptive, unstructured tetrahedral meshes enabling geometrically complex models, including curved and mutually intersecting faults. Mesh resolution can be adapted to ensure fine sampling of the faults while satisfying the requirements regarding numerical dispersion of pure wave propagation away from the fault. End-to-end computational optimization (85-88), including an efficient local time-stepping algorithm (84), allows for high efficiency on high-performance computing infrastructure. SeisSol is verified in a wide range of community bench- 
marks (89) by the SCEC/USGS Dynamic Rupture Code Verification project $(90,91)$. SeisSol is freely available (https://github.com/SeisSol/SeisSol).

\section{Model resolution}

The structural model is discretized into a computational mesh consisting of 14 million elements. Geometric resolution is set to $h=1 \mathrm{~km}$ across all faults and the mesh is coarsened away from the fault system. We choose polynomial basis functions of order $p=4$ leading to a $5^{\text {th }}$ order accurate numerical scheme in space and time. In Seissol, each dynamic rupture element face is discretized by $(p+2)^{2}$ Gauss points, enabling sub-elemental resolution of rupture dynamics. A simulation of $900 \mathrm{~s}$ of dynamic rupture and wave propagation requires $4 \mathrm{~h}$ on 5000 Sandy Bridge cores of the supercomputer SuperMucNG (Leibniz Supercomputing Center, Germany).

The process zone width $\Lambda(92)$ defined as the area behind the rupture front in which shear stress decreases from its static to its dynamic value, determines numerical convergence on the faults. In the preferred dynamic rupture scenario, the median $\Lambda$ is about $5 \mathrm{~km}$, while $95 \%$ of the fault elements feature $\Lambda$ greater than $1.5 \mathrm{~km}$. The model adequately resolves $\Lambda$ with at least 1.5 elements and polynomial basis functions of order $p=4$ (see the detailed $h / p$ refinement analysis in (88)).

We here use a relatively coarse discretization compared with high-resolution dynamic rupture models on segmented crustal fault networks (e.g., (43)), due to the large process zone width and smooth geometry of the subduction interface and splay faults.

\section{Tsunami modeling}

To model the tsunami, we use sam(oa) ${ }^{2}$ (https://gitlab.lrz.de/samoa/samoa), a highly scalable software (93) solving the shallow water equations using adaptive mesh refinement. sam(oa) ${ }^{2}$ implements a secondorder Runge-Kutta discontinuous Galerkin scheme $(94,95)$ on triangular grids. Its adaptive mesh refinement approach allows for stable and accurate simulation of large-scale wave propagation in the deep sea and small-scale wave shoaling and inundation at the shore. $\operatorname{sam}(\mathrm{oa})^{2}$ is verified (96) against Stormflash (67) over all numerical test cases described in (67). 
We use the GEBCO 2019 topography and bathymetry data set (71) with a horizontal resolution of 15 arc seconds (approximately $450 \mathrm{~m}$ ). This allows for a sufficiently accurate representation of bathymetric features in deeper sea regions, where tsunamis have large wavelengths, but is relatively inaccurate at shallow depths.

The tsunami is sourced by time-dependent bathymetry perturbations resembling the coseismic dynamic rupture seafloor displacements. In addition to the vertical displacement, we account for the effects of east-west and northsouth horizontal displacements by the linear approximation proposed by (97).

The domain of the computational tsunami model (Fig. 4c) encompasses the source region and a large part of the Indian ocean. The computational grid is initially refined near the coast at the highest resolution of about $1.7 \mathrm{~km}$. This results in an initial mesh of 3.6 million cells, which expands to more than 5 million cells during the dynamically adaptive computation. The refinement strategy is based on the gradient in sea surface height (ssh). The simulation is run for $3 \mathrm{~h} 15 \mathrm{~min}$ (simulation time).

We point out, that our hydrostatic shallow-water based tsunami modeling approach may be extended to capture also smaller-scale complexity during tsunami-genesis by e.g. allowing for a non-linear hydrodynamic response (98) or fully coupled seismic, acoustic and gravity modeling $(99,100)$.

\section{Appendix}

\section{Earthquake nucleation}

The model earthquake hypocenter is set to $30 \mathrm{~km}$ depth at the modeled subduction interface closest to the location inferred by USGS $\left(3.316^{\circ} \mathrm{N}, 95.854^{\circ} \mathrm{E}\right)$. A smooth nucleation process is achieved by reducing the friction coefficient from its static to its dynamic value over $0.5 \mathrm{~s}$ within a spherical zone surrounding the hypocenter. The forced nucleation area expands at variable speed (maximum $2660 \mathrm{~m} / \mathrm{s}$ ) $(91)$ to a maximum radius of $3.5 \mathrm{~km}$. We decrease $D_{c}$ in the hypocentral region to $0.2 \mathrm{~m}$, which allows for a smaller nucleation area. $D_{c}$ transitions linearly to its larger value of $D_{c}=2.5 \mathrm{~m}$ over $60 \mathrm{~km}$ (Fig.1a), which may reflect hierarchical rupture growth (e.g., (101)). 
Table S1: Elastic parameters assumed in the $3 \mathrm{D}$ velocity model. $\rho, \mu, \lambda, V_{p}$ and $V_{s}$ are respectively the density, the lame parameters and the $\mathrm{P}$ and $\mathrm{S}$ wave velocities. In the zone enclosing the subduction interface (fault zone, FZ) $\rho, \mu$ and $\lambda$ vary linearly between the values indicated. In the continental crust, a $1 \mathrm{D}$ layered variation is used.

$\begin{array}{lllllll} & \text { lower depth }(\mathrm{km}) & \rho\left(\mathrm{kg} / \mathrm{m}^{3}\right) & \mu(\mathrm{MPa}) & \lambda(\mathrm{MPa}) & V_{p}(\mathrm{~m} / \mathrm{s}) & V_{s}(\mathrm{~m} / \mathrm{s}) \\ \text { Continental 1 } & 6 & 2550 & 15.94 & 15.27 & 4300 & 2500 \\ \text { Continental 2 } & 20 & 2720 & 33.32 & 31.28 & 6000 & 3500 \\ \text { Continental 3 } & \infty & 2850 & 39.02 & 42.38 & 6500 & 3700 \\ \text { FZ 1 } & 10 & 2500 & 10.00 & 20.00 & 4000 & 2000 \\ \text { FZ 2 } & 15 & 2500 & 22.50 & 27.90 & 5400 & 3000 \\ \text { FZ 3 } & 30 & 2700 & 36.96 & 40.15 & 6500 & 3700 \\ \text { FZ 4 } & 50 & 2850 & 43.35 & 56.97 & 7100 & 3900 \\ \text { FZ 5 } & \infty & 3050 & 46.39 & 60.97 & 7100 & 3900 \\ \text { Oceanic 2 } & \text { meshed } & 2850 & 39.02 & 42.38 & 6500 & 3700 \\ \text { Oceanic 3 } & \text { meshed } & 3050 & 50.03 & 53.70 & 7100 & 4050 \\ \text { Oceanic 4 } & \text { meshed } & 3330 & 65.94 & 81.24 & 8000 & 4450\end{array}$

\section{D velocity model}

To ensure reproducibility, we here further detail the $3 \mathrm{D}$ velocity model of the Sumatra-Andaman region that we summarize in Methods Sec."Regional lithological structure”.

The model is based on a global model of the crust compiled from geologic and geophysical data (Crust 1.0 (70)) and is refined in the subduction region to be geometrically compatible with the subduction interface. We first partition the computational domain into 2 regions using the subduction interface geometry, described in Methods Sec. "Fault geometry". For the oceanic crust, from the west of the model to the trench, we incorporate the (smoothed) geometry of the 3 deepest layers of the crustal model (70). These layers resemble a subducted crust and are thus bent downwards parallel to the subduction interface from the trench without intersecting it. We constrain the minimum distance between each layer and the megathrust to be 6,12 , and $24 \mathrm{~km}$, respectively. Each layer is assigned average elastic parameters of Crust 1.0 as detailed in Table S1. For the continental crust, we assume a layered 1D velocity structure as detailed in Table S1. We constrain layer thickness and elasticity parameters from crustal tomography of the continental crust beneath the Andaman Island by (102).

\section{Megathrust and splay fault geometry}

Incorporating realistic fault geometries is important for dynamic rupture models driven by regional tectonic loading, as the fault geometry modulates the on-fault normal and shear tractions and therefore the rupture process. In 
particular, the steepness of the slab interface plays a major role in modulating synthetic ground displacements (65). We adopt the slab interface from Slab 1.0 (73), which assembles 3D geometries of most megathrust interfaces, constrained by seismological and geophysical observation (e.g. CMT solutions, active seismic profiles). Slab 1.0 shows that the Sunda megathrust steepens from north to south as well as from the trench to deeper depths. Since in this data set the Sunda subduction geometry is limited to below $10^{\circ}$ latitude we extend it to the north. Slab 1.0 has been recently updated to Slab 2.0 (103), which defines the Sunda interface along the full span of the 2004 rupture. Our extension agrees with the geometry of Slab 2.0.

We allow for shallow dynamic rupture in our model by intersecting the subduction interface geometry with the bathymetry and topography of the ground surface. The shallowest part of the Slab 1.0 geometry, located a few km below the ground surface, is mostly horizontal. Surface rupture during the 2004 event may have occurred on a shallow thrust fault splaying from the slab interface within the accretionary wedge, as suggested from inferred shallow patches of large fault slip (e.g., (104)). Surface rupture in our model is enabled by incorporating a short splay fault at the tip of the subduction interface, smoothly connected with the subduction interface via a depthdependent dip varying from 5 to $15^{\circ}$ and steeper at shallow depths.

\section{Far field ground displacements}

Fig. S1 complements Fig. 2e,f by showing the comparison of synthetic and geodetic ground displacements in the far field.

\section{Teleseismic model validation}

Following (43), we translate the time histories of dynamic fault slip of the dynamic rupture scenario into a subset of 50 double couple point sources ( 25 along strike by 2 along depth). We generate broadband synthetics from a Green's function database using Instaseis (105), which is based on global 2.5D axisymmetric spectral element simulations, and the PREM model (Preliminary Reference Earth Model) for a maximum period of $10 \mathrm{~s}$ and including anisotropic effects.

The in this manner rapidly computed, yet simplified, teleseismic synthetics reproduce the amplitudes and 


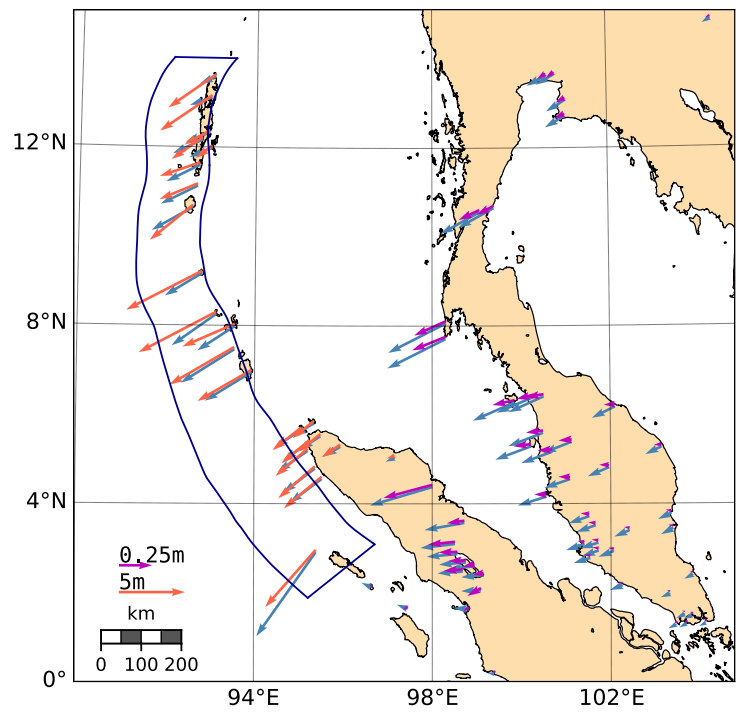

(a)

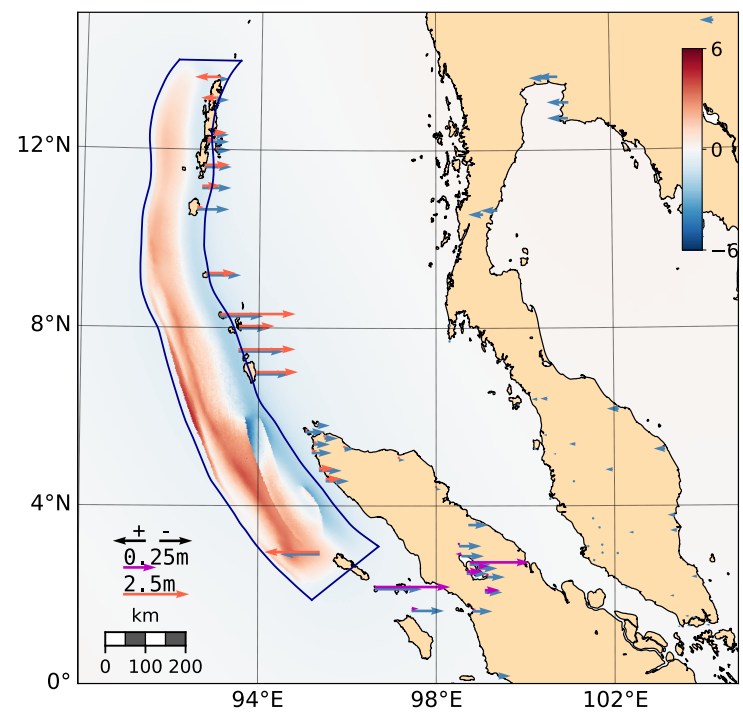

(b)

Figure S1: Comparison of synthetic ground displacements (blue) and geodetic observations (orange and magenta). In the far-field a different scaling is applied. (a) Horizontal ground displacements. (b) Vertical ground displacements. The complete uplift and subsidence resulting from the dynamic rupture scenario (in $\mathrm{m}$ ) is shown in red to blue including noticeable splay faulting signatures.

envelopes of recorded long-period teleseismic waveforms with an average rRMS of 0.8 for the preferred dynamic rupture scenario at periods of $150 \mathrm{~s}$ to $500 \mathrm{~s}$ (Fig. S2). The timing of the largest amplitude surface wave signal in the observed records at the frequency considered is well recovered by the synthetics at many stations (e.g. RAYN, DGAR, LSA, ENH), but slightly in advance at others (e.g. COCO, AIS). Amplitudes are slightly low overall compared to observations. Teleseismic surface waves are best reproduced at stations ENH, RAYN, and DGAR, which are in the direction of rupture propagation and perpendicular to it. We expect that the apparent misfits may be reduced by conducting fully $3 \mathrm{D}$ global wave simulations.

\section{Off-fault plasticity}

We account for the possibility of off-fault inelastic energy dissipation by adopting a Drucker-Prager elasto-viscoplastic rheology. The implementation is described in (88). While purely elastic dynamic rupture models require defining initial stresses acting on the fault(s) only, models with off-fault plasticity require domain-wide parametrization of initial stresses, cohesion, and friction of the bulk rock. The bulk material's internal friction coefficient $\nu$ is set equal 


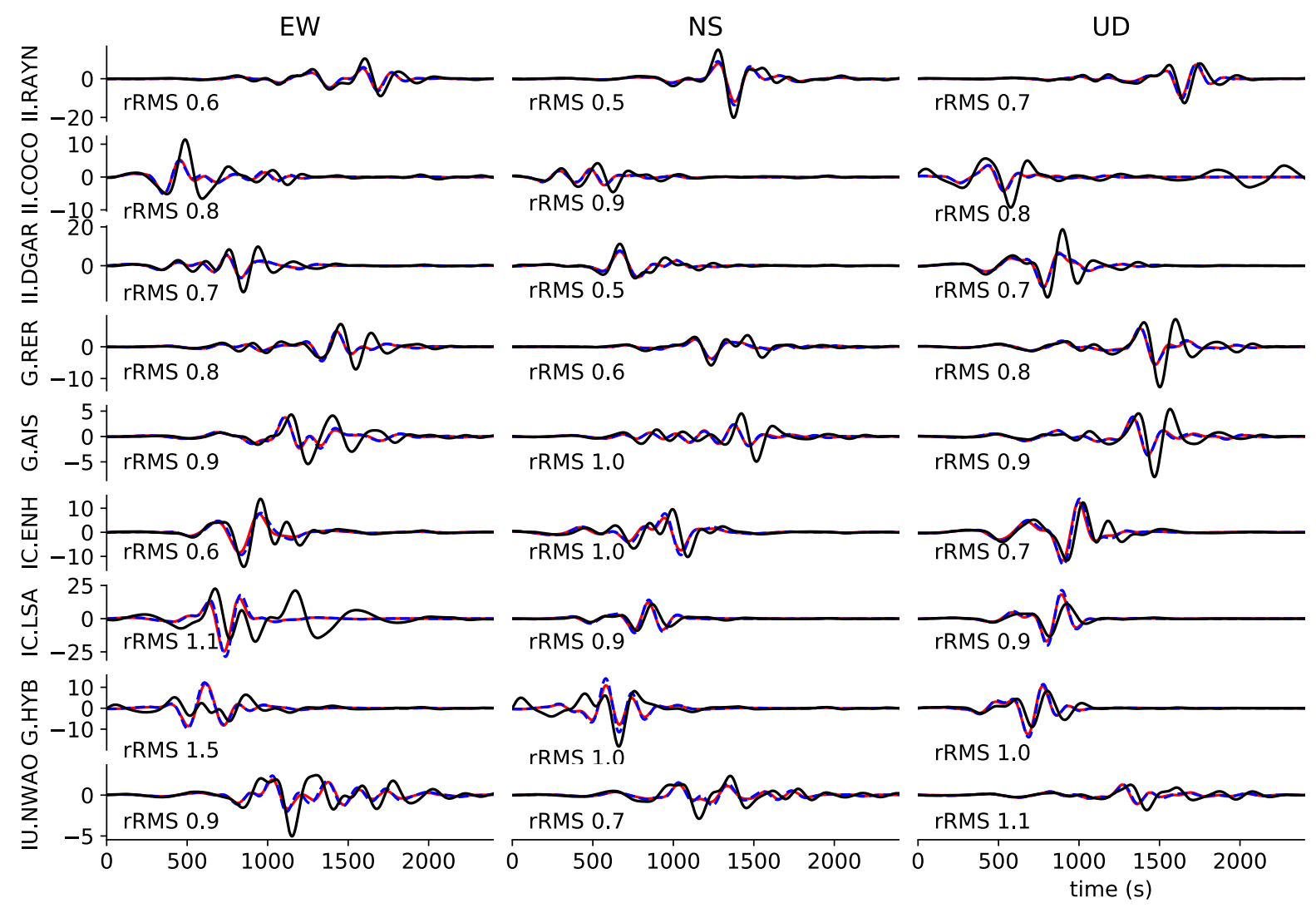

Figure S2: Comparison between synthetic (red and blue) and observed (black) teleseismic waveforms. The red traces are computed using the base scenario, while the blue traces correspond to the model of Fig. 4 featuring less off-fault yielding and more slip to the trench, yet, indistinguishable synthetics. A 150-500 s band-pass filter is applied to all traces. Station locations are shown in Fig. S3. Synthetics are generated using Instaseis (105) and the PREM model including anisotropic effects and a maximum period of $10 \mathrm{~s}$. 


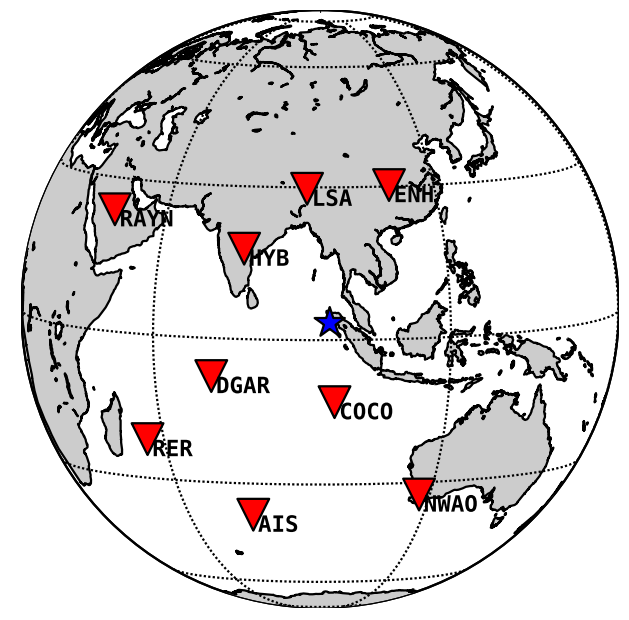

Figure S3: Locations at which synthetic data are compared with observed records in Fig. S2.

to the static fault friction coefficient, $\mu_{s}=0.6$. In the weaker sediments scenario only, we linearly decrease it at shallow depth, from 0.6 at $15 \mathrm{~km}$ to 0.2 at the sea-surface. Off-fault initial stresses resemble the depth-dependent initial stresses described in Methods Sec. "Stress state and fault friction". The viscoplastic relaxation time $T_{v}$ is set to $0.03 \mathrm{~s}$.

The bulk cohesion $C(z)$ is set as a combination of a depth-dependent term and a constant term (see Fig. S5):

$$
C(z)=C_{0}+C_{1}(z) \sigma_{c}^{\prime}
$$

$C_{1}(z)$ accounts for the hardening of the rock structure with depth, while $C_{0}$ controls localization and magnitude of off-fault yielding at shallow depth and $\sigma_{c}^{\prime}=\sigma_{c}-P_{f}$ is the effective confining stress.

We set $C_{0}$ to $1 \mathrm{MPa}$ in the base dynamic rupture scenario to represent partially consolidated sediments (35), to $0.3 \mathrm{MPa}$ for the alternative scenario featuring weaker sediments, and to $10 \mathrm{MPa}$ for the alternative model featuring stronger sediments. $C_{1}(z)=1$ for both the base model and the alternative model featuring stronger sediments, and $C_{1}(z)=\max \left(1,(z / 15000)^{2}\right)$ for the alternative model featuring weaker sediments.

Closeness to failure (see Fig. S5) is quantified by the CF ratio (e.g., (81)):

$$
C F=\frac{\sqrt{I_{2}}}{\tau_{c}}
$$




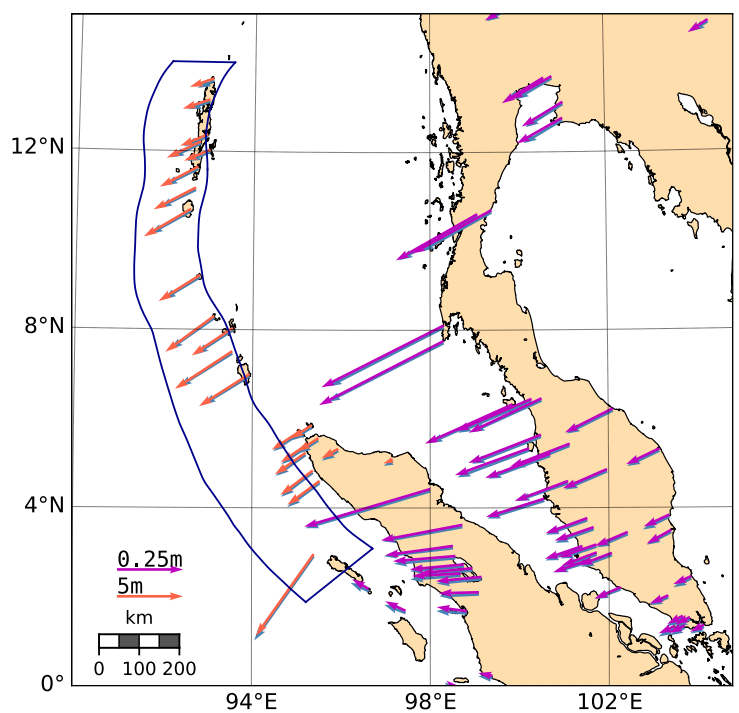

(a)

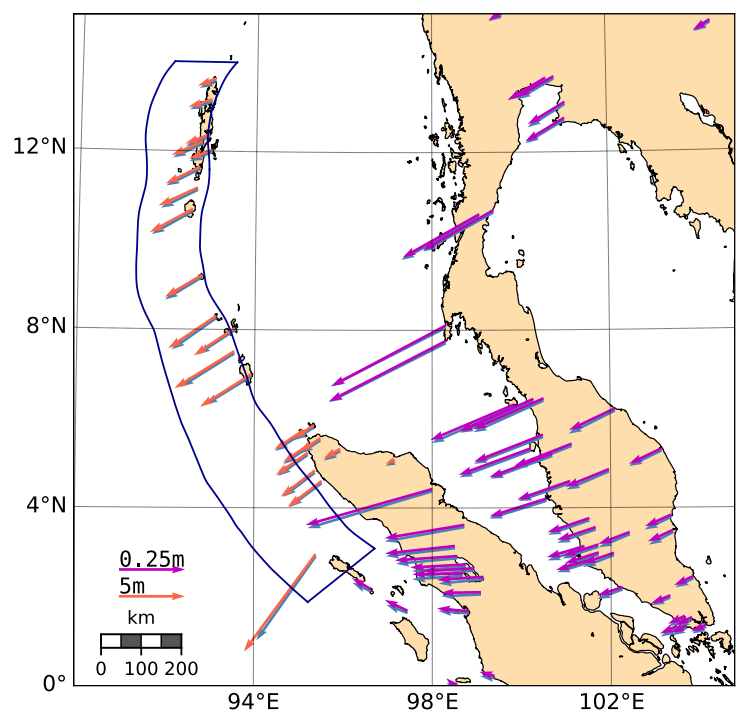

(c)

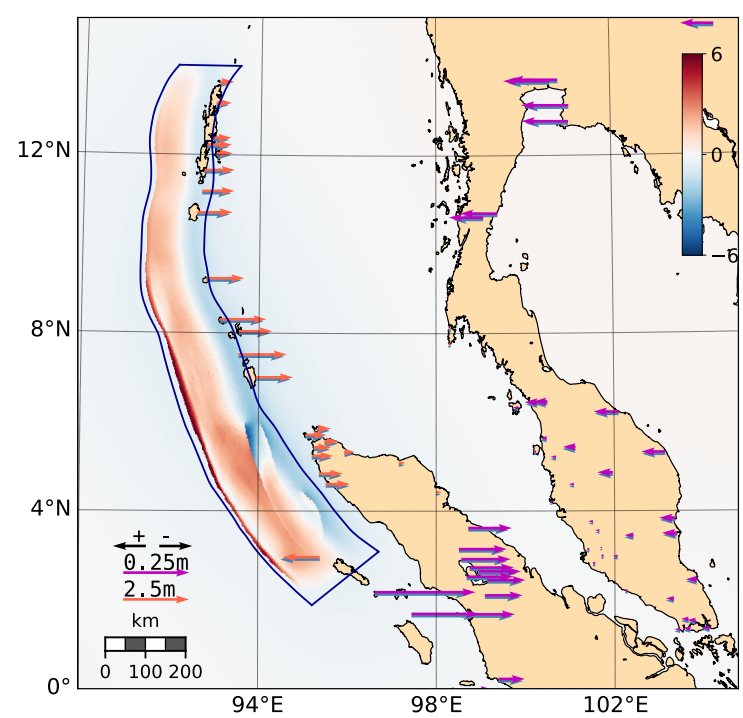

(b)

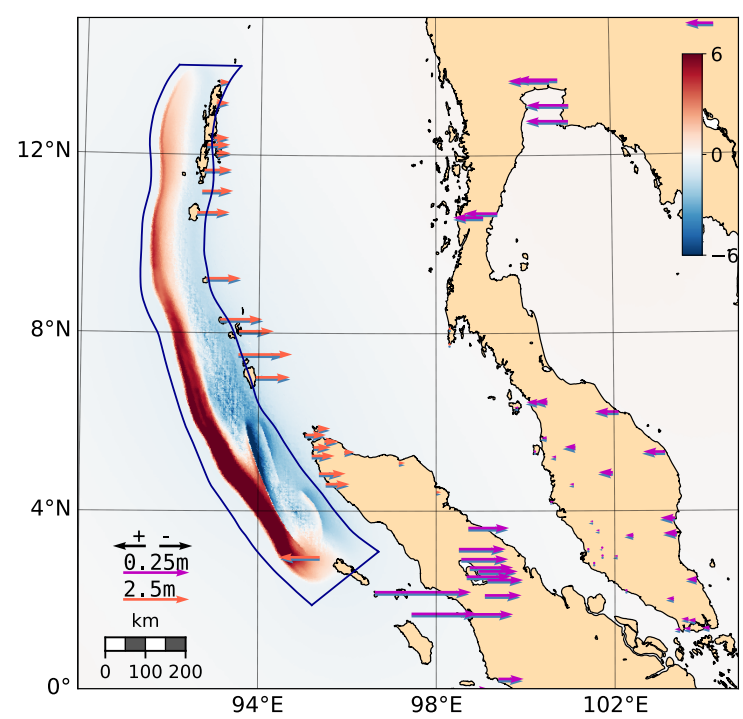

(d)

Figure S4: Comparison between ground displacements produced by the base scenario and by the two scenarios of Fig. 4 designed with alternative visco-elastic parameters, yielding weaker or stronger sediments. A different scaling is applied to highlight smaller scale distant ground displacements. In all panels, blue is the preferred scenario and orange (or magenta, depending of the scaling) is either the scenario with stronger (a, b) or weaker (c, d) sediments. $(\mathrm{a}, \mathrm{c})$ : horizontal displacements. (b,d): vertical displacements. The distribution of vertical surface displacements of the scenario with stronger (resp. weaker) sediments is shown in red to blue in (b) (resp. (d)). Note the saturated color scale: the vertical displacements range between -5.3 and $8.3 \mathrm{~m}(-9$ and $12.1 \mathrm{~m}$, respectively) for the scenario with stronger (respectively weaker) sediments. 


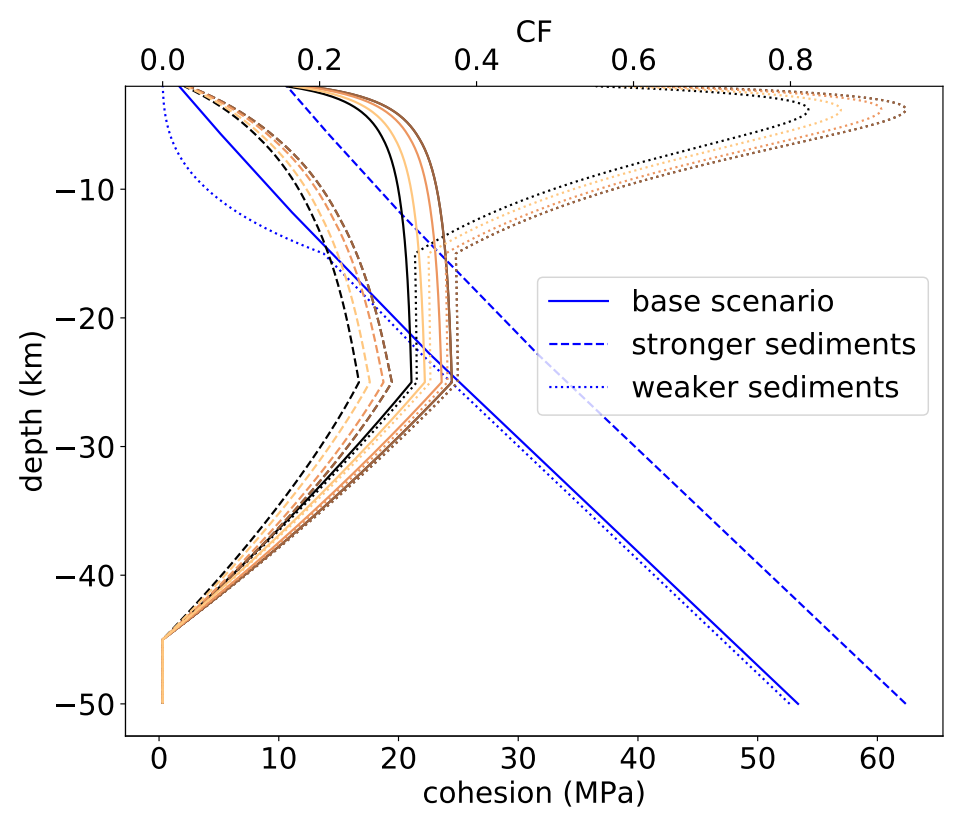

Figure S5: Depth dependence of bulk cohesion $C(z)$ (eq. 6 blue lines) and of the failure criterion CF (eq. 7, other than blue lines) at four locations along the trench (from south to north, the curves are colored in gold, orange, brown and black). Different line styles refer to different scenarios: the base scenario is represented by solid lines, the alternative scenario with stronger sediments by dashed lines, and the scenario featuring weaker sediments with dotted lines.

where $I_{2}$ is the second invariant of the deviatoric stresses and $\tau_{c}$ the Drucker-Prager yield criterion, given by:

$$
\tau_{c}=C(z) \cos (\Phi)-\sigma_{m} \sin (\Phi)
$$

with $\Phi=\arctan (\nu)$ the internal angle of friction and $\sigma_{m}=\sum_{n=1}^{3} \sigma_{i i} / 3$ the mean stress.

The such constrained CF ratio is depth-dependent and varies along-arc for all three scenarios presented, aligned with the assumed distribution of initial stresses. In the base and stronger sediment scenarios, cohesion is dominated by the constant term $C_{0}$ at shallow depth. Closeness to failure is there low, while plastic yielding is not prevented since absolute rock strength is low as well. In the weak sediment model, a quadratic reduction of cohesion $C(z)$ down to a depth of $15 \mathrm{~km}$ leads to pronounced higher closeness to failure peaking at $4 \mathrm{~km}$ depth. At larger depth, CF decreases according to the same linear increase of bulk cohesion with depth in all models. We note that even in the weak sediment model, wedge rocks are not on the verge of failure as is assumed in e.g. (45). 


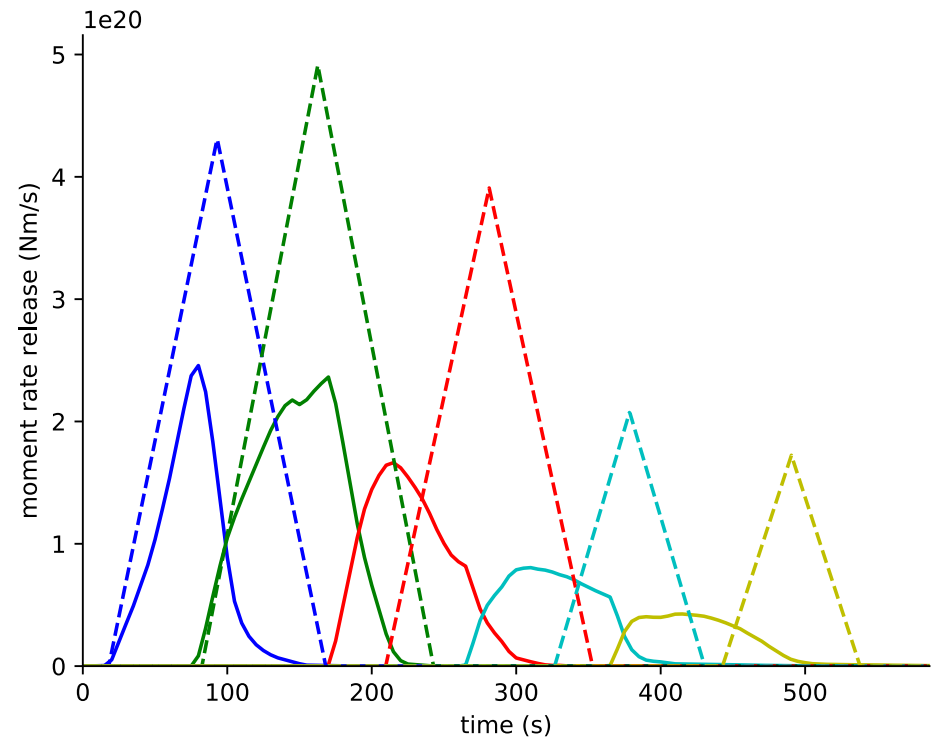

Figure S6: Comparison of a 5 point-sources model derived from the dynamic rupture scenario with Tsai et al. (21) teleseismic inversion: Moment rate release of each point source. Dashed line:Tsai et al. (21), solid line: dynamic rupture scenario. From south to north, the curves are colored in blue, green, red, cyan and yellow.

\section{Multiple point source analysis: source time functions}

In Fig. S6, we evaluate the dynamics of the base earthquake scenario in comparison to the 5 point source kinematic model of (21), which is inferred from teleseismic data. The synthetic moment released in our scenario is derived from the slip across all faults of the dynamic rupture scenario.

All five source time functions recover triangular shapes. While timing and shape of the moment released by each source match well, all amplitudes are significantly smaller than in (21). This may be due to the overall discrepancy in moment magnitude which is 9.1 in our scenario relative to the moment magnitude of 9.3 in (21) (see discussion in (26)).

\section{Rupture speed sensitivity to sediment strength}

In Fig. S7, we present the along arc-variation of rupture velocity of the two alternative scenarios. As discussed in the main text shallow rupture speed in the weak sediment scenario (upper panel) is drastically reduced in the uppermost $10 \mathrm{~km}$ averaging only $1.8 \mathrm{~km} / \mathrm{s}$, while rupture speed in deeper parts is not affected and the median rupture 


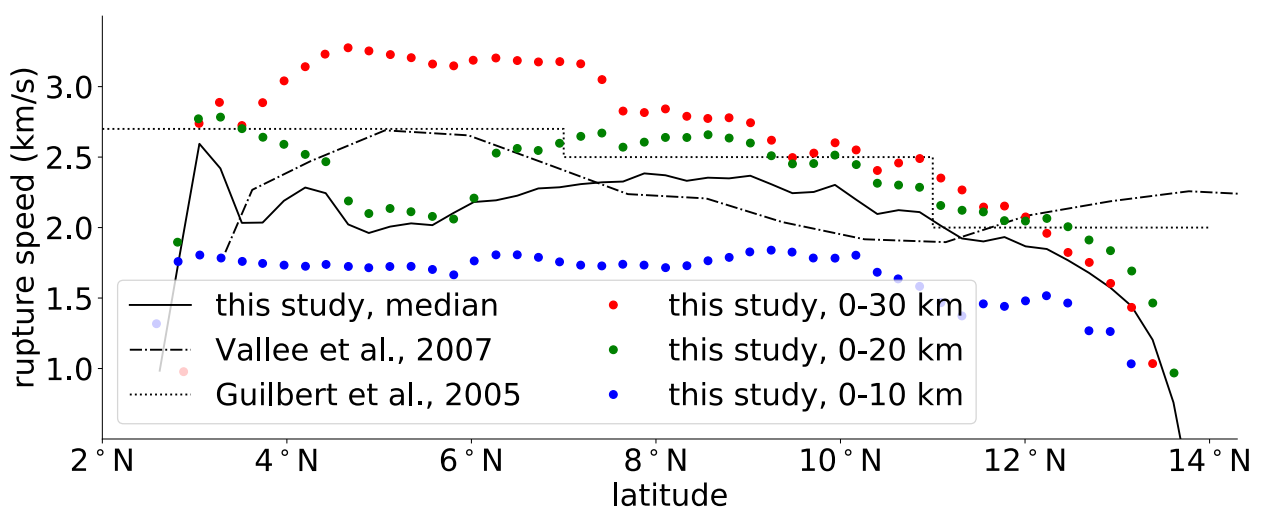

(a)

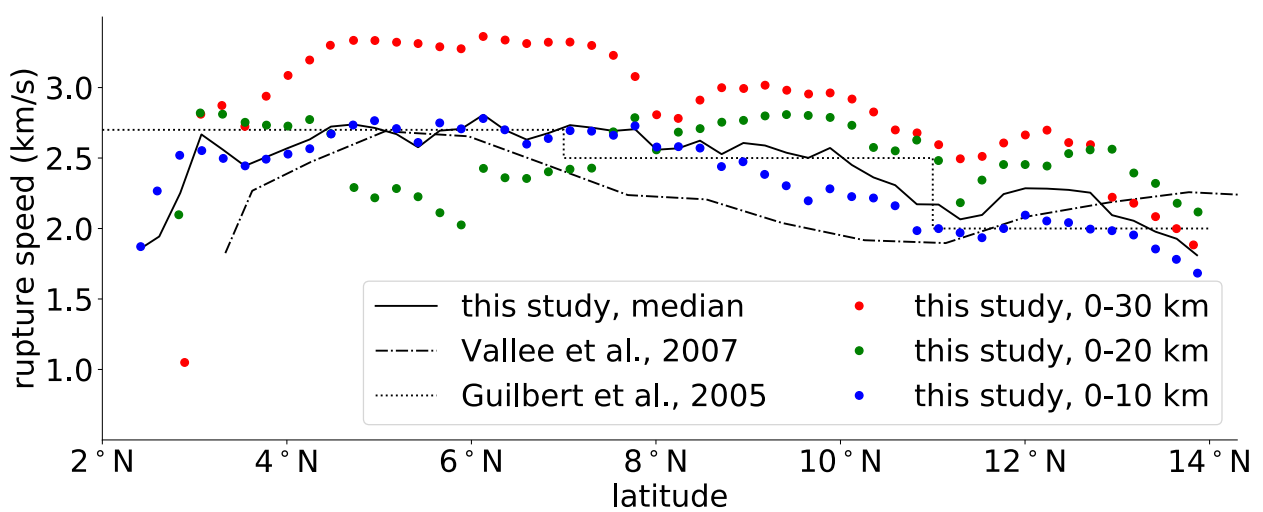

(b)

Figure S7: Sensitivity of the rupture speed to the strength of near-fault sediments. Along arc-variation of rupture velocity of two alternative scenarios designed with alternative visco-elastic parameters, yielding weaker (upper panel) or stronger (lower panel) sediments compared with inference from Rayleigh waves (50) and from acoustic data $(51)$.

speed remains comparable to observations and other scenarios. The stronger sediment scenario is characterized by shallow supershear rupture, with shallow rupture speeds close to the fault median values, partially exceeding speeds at larger depth.

\section{Nearly optimal orientation of faults}

Fig. S8 depicts fault strength in terms of the ratio of initial shear stress $\tau$ over effective normal stress $\sigma_{n}^{\prime}$ for all models. We show that the absolute variations in prestress magnitude are small, and that the subduction interface is nearly optimally oriented. To highlight the effect of the subduction interface geometry, the modulation of the 
a)

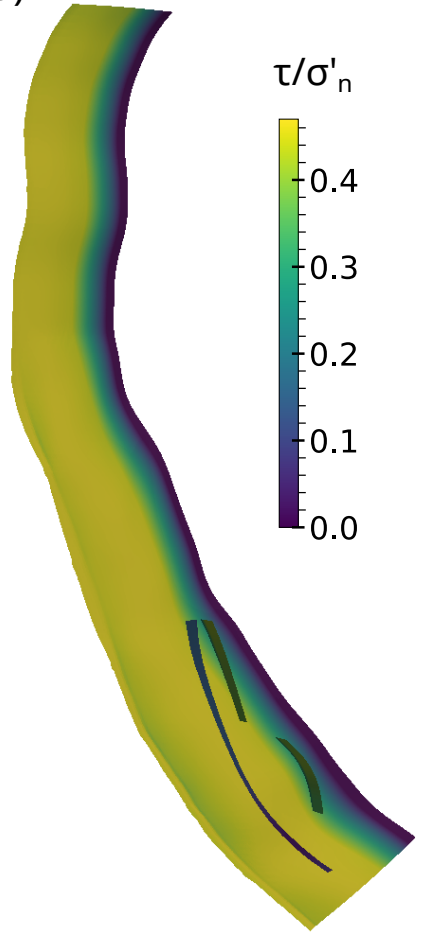

b)

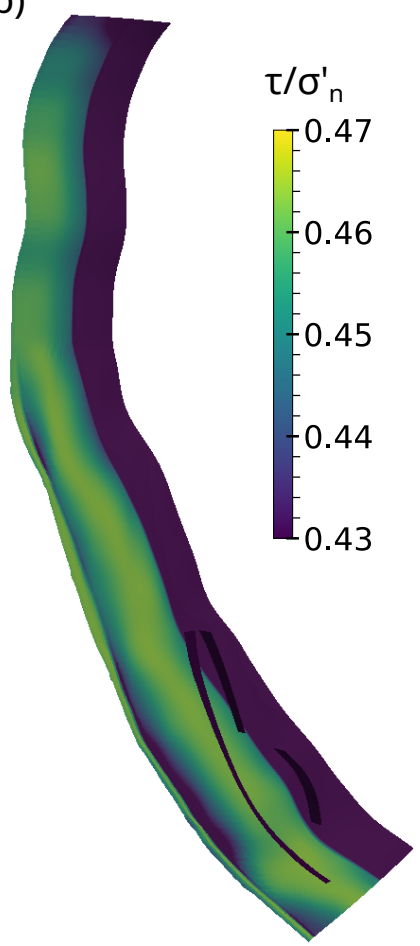

Figure S8: Ratio of initial shear stress $\tau$ over effective normal stress $\sigma_{n}^{\prime}$. (a) $\tau / \sigma_{n}^{\prime}$ distribution plotted with a colormap covering the whole range of variation of $\tau / \sigma_{n}^{\prime}$. (b) $\tau / \sigma_{n}^{\prime}$ distribution plotted over a much narrower colormap range, highlighting the (limited) variations of $\tau / \sigma_{n}^{\prime}$ over the earthquake rupture area

relative prestress $R_{0}$ by the magnitude of the convergence rate, and the decrease of $R_{0}$ south of the hypocenter are not accounted for when calculating $\tau$ and $\sigma_{n}^{\prime}$.

\section{Supplementary Movies}

We provide several animations illustrating the earthquake and tsunami scenarios at https://syncandshare. lrz.de/getlink/fit4a9XQmausR5TE47GqB4GT/.

Sumatra_faultslip_3models.avi is an animation showing the rupture dynamics of three earthquake scenarios discussed, in terms of absolute fault slip (m) across the fault network, side by side.

Sumatra_base_SR.avi is an animation showing the rupture dynamics of base earthquake scenario, in terms of absolute slip rate (m) across the fault network. 


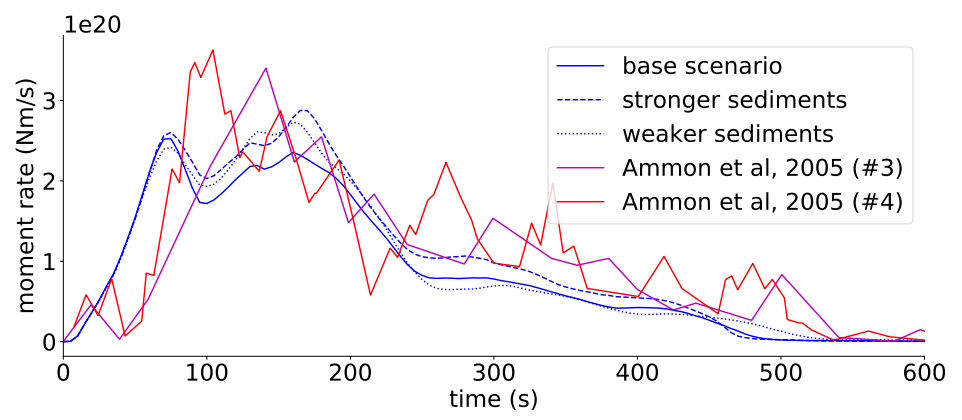

Figure S9: Comparison of moment rate release of the base scenario, the two scenarios of Fig. 4 designed with alternative visco-elastic parameters, yielding weaker or stronger sediments and observational inferences from teleseismics (17)

We also provide animations of the tsunami scenarios associated with the three earthquake scenarios discussed: base (tsunamiBaseScenario.avi), stronger sediments (tsunamiStrongerSediments.avi) and weaker sediments (tsunamiWeakerSediments.avi) scenarios. The tsunami animations show the evolution of the sea surface height amplitudes (in meter) as predicted by each tsunami scenario. 